\title{
Processing of Color, Form and Disparity Information in Visual Areas VP and V2 of Ventral Extrastriate Cortex in the Macaque Monkey
}

\author{
Andreas Burkhalter ${ }^{1}$ and David C. Van Essen \\ Division of Biology 216-76, California Institute of Technology, Pasadena, California 91125
}

\begin{abstract}
The responses of single cells to light bars of different orientation, direction of motion, speed, binocular disparity, and wavelength were systematically analyzed in areas V2 and VP of ventral extrastriate visual cortex in the macaque monkey. Selectivity for each of these parameters was assessed quantitatively using computer-controlled procedures. In both VP and V2 (both representing the superior contralateral quadrant), more than half of the cells studied were selective for stimulus color and more than half for stimulus orientation. In contrast, only a small minority of the VP and V2 cells were selective for the direction of stimulus motion. Comparison with reports of single-unit properties in dorsal extrastriate cortex suggests there are no major differences in the incidence of orientation, direction, and color selectivity between ventral and dorsal subdivisions of $\mathrm{V} 2$. Between V3 and VP, though, there are marked differences: Colorselective cells are much less common in V3 than VP, whereas direction-selective cells are more common in V3. This dorsoventral difference in the distribution of neuronal response properties suggests a significant asymmetry in the way visual information is processed in upper and lower parts of the visual field. The properties of cells in VP suggest that it plays an important role in both form and color vision, similar to that attributed to area V4.
\end{abstract}

The visual cortex in primates consists of many distinct areas, most of which contain separate representations of the visual field (see Van Essen, 1985). For those areas whose borders can be identified reliably, it is of obvious interest to examine the receptive field properties of their constituent neurons, thereby contributing to the understanding of how sensory information is distributed and processed within cortex.

Studies of the responses of single neurons to a variety of visual stimuli have provided evidence for important functional specializations in different extrastriate areas. For example, the middle temporal (MT) area contains a high percentage of cells selective for direction, speed, and binocular disparity, but not for color or shape, suggesting that it is specialized for the analysis of visual motion (Baker et al., 1981; Maunsell and Van Essen, 1983a, b; Zeki, 1974a, b). Area V4 contains a substantial percentage of color-selective cells, suggesting a role of this area in color vision (Zeki, 1978, 1983a). However, many cells in V4 lack obvious color selectivity (Schein et al., 1982; Van Essen

\footnotetext{
Received Oct. 15, 1985; revised Jan. 30, 1986; accepted Feb. 5, 1986.

We are grateful to $C$. Shotwell and $K$. Tazumi for histological work and preparation of figures, H. Adams and M. Walsh for excellent equipment design and construction, C. Oto and L. Rodriguez for typing, and E. DeYoe, J. Maunsell, and D. Felleman for comments on the manuscript. This work was supported by NIH Grant EY 02091, a fellowship from the Fogarty International Center (A.B.), and the Swiss National Science Foundation (A.B.).

Correspondence should be addressed to Andreas Burkhalter, Department of Neurology and Neurological Surgery, Box 8057, Washington University School of Medicine, 660 S. Euclid Ave., St. Louis, MO 63110.

Copyright (C) 1986 Society for Neuroscience $0270-6474 / 86 / 082327-25 \$ 02.00 / 0$
}

and Zeki, 1978), suggesting that it is not simply a "color area." Moreover, color-selective cells are found in areas other than V4 and direction-selective cells in areas other than MT (Baizer, 1982; Baizer et al., 1977; DeYoe and Van Essen, 1985; Hubel and Livingstone, 1985; Livingstone and Hubel, 1984; Shipp and Zeki, 1985; Zeki, 1978). Thus, it is unlikely that each visual area plays an exclusive role in analyzing any particular parameter or stimulus dimension. It may be more appropriate to think in terms of distinct functional streams that arise in striate cortex (V1) and course in parallel through a hierarchy of visual areas that can be identified on the basis of patterns of interconnections (Ungerleider and Mishkin, 1982; Van Essen and Maunsell, 1983).

In order to refine and extend these notions about functional processing, it is essential to have accurate descriptions of the properties of cells in each visual area. In the present study, we have examined the receptive-field properties of cells in 2 visual areas, V2 and VP (the ventral posterior area), in ventral extrastriate cortex of the macaque monkey. We chose to record from ventral extrastriate cortex because very little was known about the physiological properties of cells in this region and because of the possibility that there might be functional counterparts to several dorsoventral asymmetries in anatomical organization that have recently been described. In particular, we have suggested that V2 is bordered by 2 distinct areas, V3 dorsally and VP ventrally, that differ in their connections (V1 projecting to V3 but not to VP), their myeloarchitecture, and their pattern of callosal inputs (Burkhalter et al., 1986; Van Essen et al., 1979, 1982, 1986). In our opinion these differences are substantial enough to warrant the use of separate names for each region, even though the resultant areas represent only part of the contralateral visual hemifield (lower fields in V3, upper fields in VP).

We report here on the selectivity of single units in VP and ventral V2 for a variety of stimulus parameters (orientation, wavelength, direction, speed, and binocular disparity). Responses were analyzed quantitatively in order to avoid observer bias and to preclude $a$ priori classification into groups that might not be biologically genuine. The most striking result from our recordings is the finding of a high incidence of color-selective cells in both VP and ventral V2. This contrasts with a much lower incidence of color sclcctivity reported for V3 (Baizer, 1982; Felleman et al., 1984; Van Essen and Zeki, 1978; Zeki, 1978), implying a significant asymmetry in the way visual information is processed in upper versus lower parts of the visual field.

\section{Materials and Methods}

\section{Animal preparation}

Four macaque monkeys (Macaca fascicularis) between 3.1 and $4.2 \mathrm{~kg}$ were used in a semichronic recording preparation, similar to that described by Maunsell and Van Essen (1983a). Under pentobarbital anesthesia, a stainless steel cylinder ( $2 \mathrm{~cm}$ diameter) was implanted over a hole in the skull, leaving the dura intact. Most of the recordings in 
ventral V2 came from 2 animals in which the hole was centered over the operculum of $\mathrm{V} 1$, about $12 \mathrm{~mm}$ lateral to the sagittal suture and 10 $\mathrm{mm}$ dorsal to the occipital ridge. The axis of the chamber was parallel to the sagittal plane and tipped ventrally by $30^{\circ}-40^{\circ}$. A more favorable access to large parts of VP in the inferior occipital sulcus (IOS) and the occipitotemporal sulcus (OTS) was chosen in 2 other cases. In these 2 , the hole was centered over foveal striate cortex, about $25 \mathrm{~mm}$ lateral to the midline and $12 \mathrm{~mm}$ dorsal to the occipital ridge. The chamber was angled by about $45^{\circ}$ from the horizontal and $30^{\circ}$ from the sagittal plane. This facilitated the tracing of the topographic progression from $\mathrm{V} 2$ to VP in the course of different penetrations. In addition, the placement allowed easy access to both banks of the IOS and of the OTS, thus making it possible to record in a single penetration over a wide range of eccentricities.

Starting several days after initial surgery, recordings were conducted in twice-weekly sessions for up to 7 weeks, each session lasting 10-12 hr. In 3 animals, a final acute recording session was made with the chamber implanted at a mirror symmetrical location over the opposite hemisphere. During recording sessions, animals were paralyzed with a continuous infusion of flaxedil $(7.5 \mathrm{mg} / \mathrm{kg} / \mathrm{hr}$, i.p.) and respired on a mixture of $70 \%$ nitrous oxide, $27.25 \% \mathrm{O}_{2}$ and $2.75 \% \mathrm{CO}_{2}$. The body temperature was maintained at $37^{\circ} \mathrm{C}$, and the electrocardiogram was monitored throughout the experiment.

The electrode was mounted on a $X / Y$ stage equipped with a microdrive, which was coupled to both the recording chamber and the air table. Recordings were performed through a small opening in the dura using 0.4-1.2 M $\Omega$ varnished tungsten electrodes and conventional equipment for amplification and display of the signal. Each penetration was labeled with one or more electrolytic lesions $(10 \mu \mathrm{A}$ for $10 \mathrm{sec})$ made at appropriate depths near the recording sites. The eyes were covered with contact lenses, the pupils were dilated with atropine $(2 \%)$, and cycloplegia was achieved with neosynephrine $(2.5 \%)$. Correcting lenses were used to focus the eyes on the screen. Eye shutters attached to artificial pupils ( $8 \mathrm{~mm}$ diameter) were placed in front of the eyes. The positions of the foveas were determined with a reversing-beam ophthalmoscope. A prism of appropriate strength and orientation was used to superimpose the left and the right foveas to within $0.5^{\circ}-1^{\circ}$.

After $8-10 \mathrm{hr}$ of recording, paralysis was stopped and a 5\% glucose infusion begun; 1-2 hr later, recovery was initiated with an injection of atropinc $(0.15 \mathrm{mg} / \mathrm{kg})$, followed by ncostigmine $(0.25 \mathrm{mg} / \mathrm{kg}) 10 \mathrm{~min}$ later. Shortly thereafter, spontaneous respiration resumed and the animal was returned to its cage.

\section{Visual stimulation}

The optical projection system used in these experiments was the same as already been described by Maunsell and Van Essen (1983a, b). Its design allowed manual and computer control over a variety of stimulus parameters, with the basic stimulus being a stationary or moving slit of controlled length, width, orientation, direction, velocity, binocular disparity, luminosity, and wavelength.

The light source for most experiments was a $1200 \mathrm{~W}$ bulb (Sylvania, BRN) housed in a modified projector (Selectroslide; Spindler and Sauppe Inc., North Hollywood, CA). A rotatable slit diaphragm was interposed in the light beam to provide variable length, width, and orientation. Colors were obtained by filtering the light with broadband Wratten filters (Kodak) or narrow-band interference filters (Rolyn Optical). A cube prism split the beam so that 2 slits were projected onto the screen by pairs of galvanometer-controlled mirrors. The 2 beams were passed through cross-polarized filters, projected onto a planar, nondepolarizing screen at $114 \mathrm{~cm}$, and viewed by the animal through a second pair of cross-polarized filters (Cynader and Regan, 1978). This arrangement ensured that each eye saw only one image of a color effective in driving the cell and at a disparity that could be varied during tests of disparity selectivity or set at the optimal disparity for other tests. Except when testing for color selectivity, stimulus luminance was normally 1.0-1.5 $\log$ units above the photopic background illumination $\left(10 \mathrm{~cd} / \mathrm{m}^{2}\right)$.

In tests for color selectivity, the cross-polarized filters were removed and the nondepolarizing screen replaced by a screen coated with a white pigment containing 95\% titanium dioxide (Krylon, No. 1502). This ensured uniform reflectance (within $0.1 \mathrm{log}$ unit) in the spectral range of our narrow-band colored stimuli. This arrangement restricted the tests for color selectivity to stimuli at approximately zero disparity. In these tests we used a set of narrow-band stimuli adjusted to have equal luminosity. The projector bulb was operated at its maximal voltage, corresponding to a color temperature of about $5500^{\circ} \mathrm{K}$. A $40 \mathrm{~W}$ tungsten source $\left(2650^{\circ} \mathrm{K}\right.$ ) with a -131 mired correction filter (Wratten No. $80 \mathrm{~A}$, Kodak) provided diffuse illumination of the screen. Narrow-band stimuli between 460 and $660 \mathrm{~nm}$ were produced by inserting 1 of 12 available interference filters. Each filter's peak transmission and full bandwidth at half-maximum $(8-10 \mathrm{~nm})$ was determined with a spectrophotometer and found to deviate from the nominal value by no more than $4 \mathrm{~nm}$ (see legend to Fig. 4). The nominal spacing between transmission peaks was $20 \mathrm{~nm}$, except in the range of $560-580 \mathrm{~nm}$, where an additional filter at $570 \mathrm{~nm}$ was used to give a $10 \mathrm{~nm}$ spacing in the region of maximal hue discrimination. Luminosity of the colors was determined by measuring illuminance on the screen (Tektronix, illuminance probe $\mathrm{J}-6503$ ) and converting footcandles into $\mathrm{cd} / \mathrm{m}^{2}$ by multiplication with the screen's reflectivity and the cosine of the incident angle. Care was taken to filter the infrared when taking the measurements. These numbers furnished the corrections needed to match stimuli for equal photopic luminosity, within 0.1 log unit, by inserting appropriate neutral density filters (Wratten, Kodak). The spectral content of the white stimulus was corrected with a -112 mired filter (Wratten No. 80B, Kodak) to achieve relatively uniform energy $\left(\mu \mathrm{W} / \mathrm{cm}^{2}\right)$, within $0.15 \log$ units, between 460 and $660 \mathrm{~nm}$. The white's photopic luminosity was matched to the monochromatic stimuli. With artificial pupils of $8 \mathrm{~mm}$ diameter, the maximal retinal illumination produced by these stimuli was 200 troland above the background illumination of 50 troland.

To attenuate stimuli, a combination of neutral density filters (Wratten, Kodak) was used, which allowed dimming in increments of 0.1 log unit over the full operating range of the system. The transmittance of the neutral density filters, measured using an irradiance probe (Tektronix, $\mathrm{J}-6502$ ) and interposed interference and heat filters, was confirmed to be independent of wavelength (within $0.1 \log$ unit) between 460 and $660 \mathrm{~nm}$. Attenuation of $2.0 \log$ units was necessary to bring the equiluminant stimuli to human psychophysical threshold for detection above the background illumination. From our own inspection of stimuli at attenuation levels close to threshold, we confirmed that the luminosities at all settings, including white, were matched to one another. At threshold the monochromatic stimuli appeared colored, confirming that they were being detected photopically, not scotopically.

Single units were isolated by triggering the oscilloscope sweep on the background activity and looking for unitary responses well above background. The window discriminator was set slightly below the single unit peak, so as to minimize contamination from low-amplitude signals while allowing flexibility for small fluctuations in size of the isolated unit. Between test series, the isolation quality was checked and, if necessary, the discriminator threshold adjusted to compensate for drifts in spike height.

Once a unit was isolated, the minimal response field was plotted for each eye, using what was judged qualitatively to be the most effective stimulus configuration. When necessary, for this purpose, colors were produced by inserting broadband filters (Wratten, Kodak) into the light path. The receptive field positions for left and right eyes were brought into register using a rotatable prism placed in front of one eye. Field positions and qualitatively assessed stimulus requirements were then entered into the computer (DEC PDP 11/34A), which controlled stimulus presentation. Quantitative testing was normally started with tests for motion parameters using white or broadband colored stimuli. In tests for direction of motion, a bar was moved through the receptive field with an orientation orthogonal to the direction of movement. All parameters were fixed except the direction of motion, which was varied pseudorandomly at intervals of $30^{\circ}$. For some cells, tests for stimulus orientation were carried out with stationary flashed bars presented at intervals of $30^{\circ} \mathrm{C}$. Whichever stimulus mode, stationary or moving, turned out to be more effective was used in subsequent tests for binocular disparity and color. In these, the optimal values for direction and speed or orientation were used and the variable was disparity (increments of 0.5 or $1^{\circ}$ ) or wavelength (increments of $20 \mathrm{~nm}$ ), respectively. Testing of color selectivity in the majority of cells was done at 2-8 different levels of stimulus luminosity, usually in increments of 0.3 or $0.4 \log$ units. It began with a series run at or near maximal luminosity and proceeded to a series run at progressively lower luminosity until the cell became unresponsive at all wavelengths. Some of these data were then used to derive action spectra (see Results). Occasionally a cell's color preference was not qualitatively judged accurately or became evident only after quantitative testing. When necessary to obtain reliable tuning curves, tests that had initially been done with white light were repeated with colored stimuli. Often, recording was stable for hours, and the unit's spontaneous discharge remained relatively steady during the $2-3 \mathrm{hr}$ 


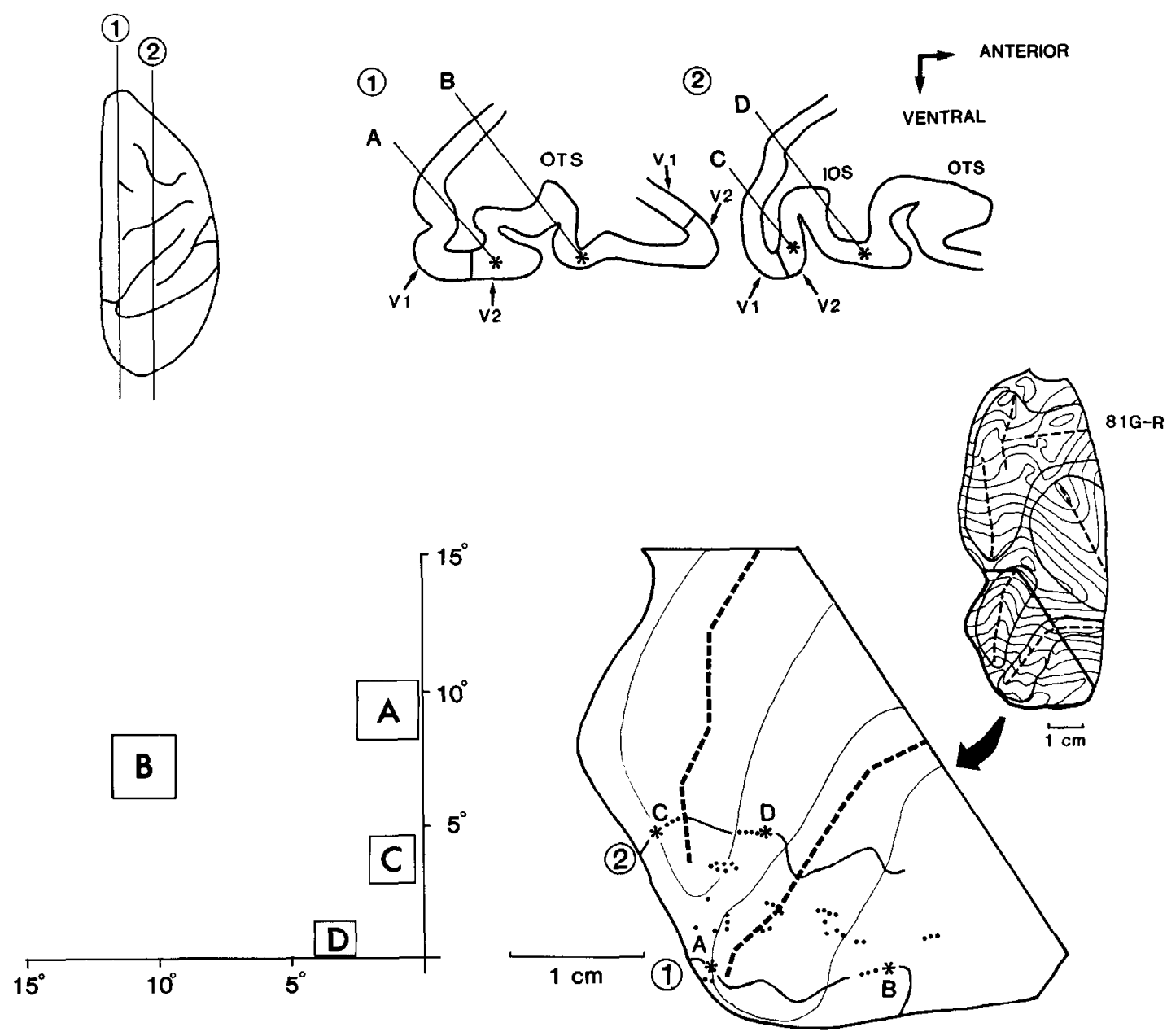

Figure 1. Location of recording sites in ventral V2. Upper right, Locations of 4 selected units $(A-D$, asterisks) are shown on parasagittal sections taken at the mediolateral levels indicated in the top view of the hemisphere at upper left $(1$, medial; 2 , lateral). Units $\mathrm{A}$ and $\mathrm{C}$ were recorded, respectively, on the posterior banks of the occipitotemporal sulcus (OTS) and inferior occipital sulcus (IOS) near the V1/V2 border. Their receptive fields (lower left ) were located near the representation of the vertical meridian. Relatively large peripheral receptive fields are represented medially (unit A); the smaller, more central fields are mapped laterally (unit C). Units B and D were recorded on the gyri anterior to units A and C. As shown on the lower left, the receptive field of unit B was located between the vertical and horizontal meridians at an eccentricity similar to unit A. The field for unit $\mathrm{D}$ was at a more central location on the horizontal meridian. Lower right, A 2-dimensional map of ventral extrastriate cortex, showing the location of recording sites A-D (asterisks), mapped on the contours (layer 4) of sections 1 and 2 (arrows). The location of this ventral portion of the map relative to the rest of extrastriate visual cortex is indicated by the bold outline in the map on center right. Recording site $\mathrm{D}$ (horizontal meridian) indicates the anterior border of central V2. Dots indicate the locations of additional recording sites in the posterior and anterior banks of the IOS and OTS in this hemisphere.

required to complete analysis. Many units, however, were lost before they had been fully examined.

\section{Data analysis}

The spike data were stored and processed in the same way as described by Maunsell and Van Essen (1983a). After completion of each test series (3-5 repetitions of each stimulus), the computer generated a printout of average impulse rate and SE for each variable. This was helpful to direct the course of further testing. The final data analysis was done on the basis of off-line generation of poststimulus time histograms, average response curves, and calculation of selectivity indices for each parameter.

\section{Histology}

During the final chronic recording session, an injection of HRP and ${ }^{3} \mathrm{H}$ proline was made into VP or ventral V2. Two days later, the splenium of the corpus callosum was cut and the recording chamber transferred to the opposite hemisphere. After another $2 \mathrm{~d}$, a final acute session, lasting 2-3 d, was carried out in which recordings were made from the second hemisphere, and a second tracer injection was made into VP or
V2. The results of these anatomical experiments will be reported elsewhere (Burkhalter and Van Essen, 1983, and unpublished observations). The animal was then deeply anesthetized with Nembutal and perfused with $0.1 \mathrm{M}$ phosphate buffer followed by $4 \%$ phosphate-buffered paraformaldehyde. The brain was blocked and allowed to equilibrate in buffered $30 \%$ sucrose. Frozen sections were cut at $31 \mu \mathrm{m}$. Reconstructions of electrode tracks were made from Nissl-stained sections. Sections from 3 brains with successful callosotomy were stained for degenerating fiber terminals (Wiitanen, 1969) in order to identify the anterior border of VP (Burkhalter et al., 1986; Newsome et al., 1980, 1986). Anatomical data were plotted on 2-dimensional cortical maps prepared according to the procedure of Van Essen and Maunsell (1980).

\section{Results}

\section{Identification of recording sites in $V 2$ and $V P$}

This report is based on a quantitative analysis of properties of 172 single units from 50 electrode penetrations in the inferior occipital sulcus (IOS), occipito-temporal sulcus (OTS), and oc- 

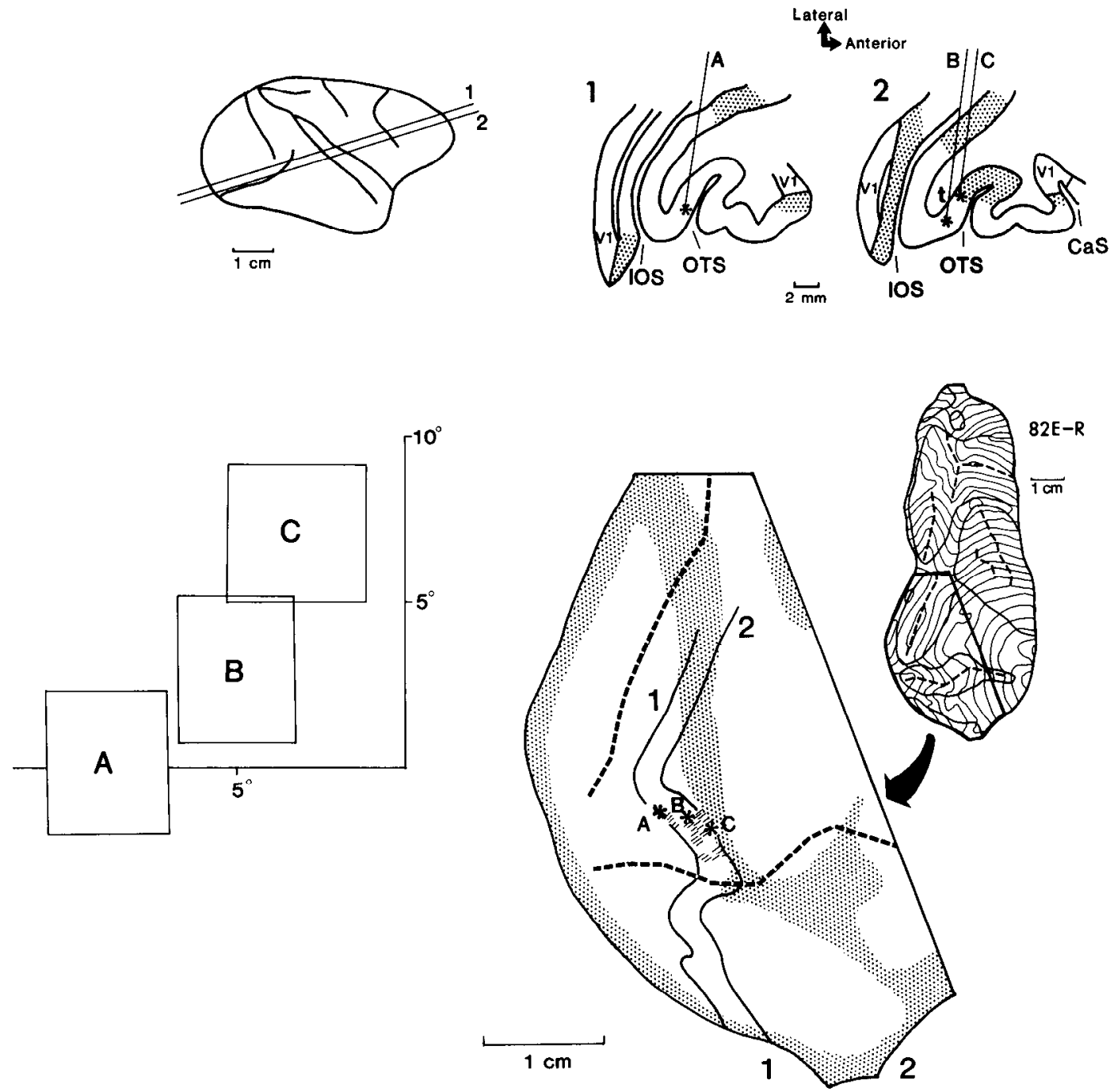

Figure 2. Location of recording sites in VP. Upper right, Histological reconstruction of recording sites (units $A-C$, asterisks) from sections cut in the plane indicated on the lateral view of a macaque brain (upper left). All 3 recordings were made from the occipitotemporal sulcus (OTS) at similar eccentricities. Recording site A, at the lateral lip of the OTS, had a receptive field at the horizontal meridian representation (lower left). Becausc the ficld was much larger than fields at comparable eccentricities in V2 (Fig. 1), this site was assigned to VP. Site B, also on the lip of the OTS but farther ventroanterior, had a receptive field entirely within the superior quadrant. Site $C$, at the margin of the zone of callosal input (stippling) near the fundus of the OTS, had a receptive field near the vertical meridian. The locations of sites A-C (asterisks) are plotted on a 2-dimensional map (lower right) of ventral extrastriate cortex. (Sites B and C were on slightly different sections, as is apparent on the cortical map, but for simplicity they are represented on the same section outline on the upper right.) Stippling indicates the location of callosal input; dashed lines, locations of recording sites assigned to VP on the basis of topographic organization and relationship to callosal inputs. Not indicated on the map are a few additional recording sites anterior to VP, where we avoided taking quantitative data if it was clear from the topography known at the time of recording that the sites were outside VP.

cipitotemporal gyrus. Of these, 60 were assigned to V2 and 112 to VP on the basis of recording site location and receptive field size and position. The way in which these assignments were made is illustrated in the first 2 figures. Figure 1 shows results from a hemisphere in which recordings were made in ventral V2 with a series of penetrations oriented in the parasagittal plane. At the upper right are outlines of 2 sections taken at the mediolateral levels indicated on the adjacent hemisphere drawing (upper left). In section 1, recording site A (asterisk) was close to the $\mathrm{V} 1 / \mathrm{V} 2$ border and, as expected from previous studies (Gattass et al., 1981), the receptive field was close to the superior vertical meridian at an eccentricity of $9^{\circ}$ (lower left panel). Recording site B was well away from the superior vertical meridian at a slightly greater eccentricity $\left(13^{\circ}\right)$. A similar progression occurred in section 2 , except that the receptive fields for sites $\mathrm{C}$ and $\mathrm{D}$ were less eccentric, as expected from their more lateral location in the hemisphere.

The relationships of recording sites to one another and to the borders of V 2 are easier to ascertain on a 2-dimensional cortical map, as shown on the lower-right panel of Figure 1. The inset shows a complete map of extrastriate visual cortex in the occipital lobe and parts of the temporal and parietal lobes, with thin lines representing layer 4 contours from a series of evenly spaced sections and dashed lines representing fundi of sulci. The expanded view of ventral occipital cortex includes contours from the 2 sections illustrated above (heavy solid lines), recording sites A-D (asterisks), and additional recording sites from this hemisphere (dots). The full width of V2 in this region is about $1 \mathrm{~cm}$, as determined from the separation between the $\mathrm{V} 1 / \mathrm{V} 2$ border, representing the vertical meridian, and site $\mathrm{D}$, repre- 


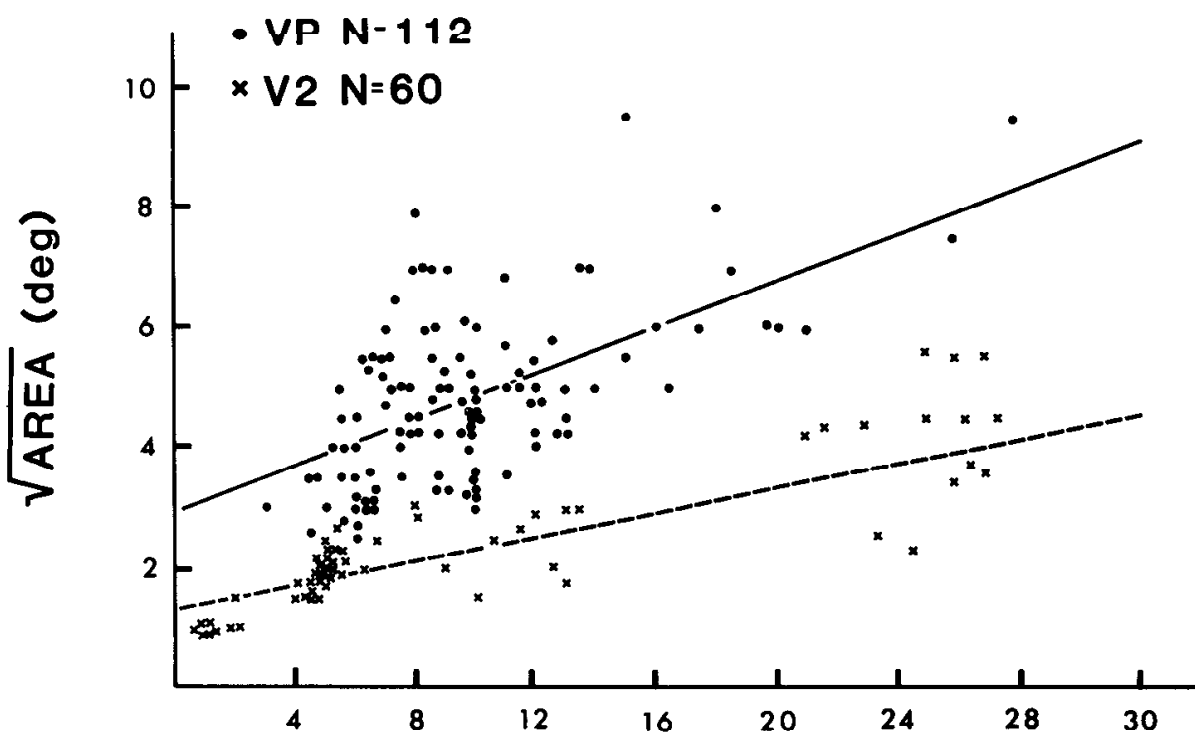

ECCENTRICITY (deg)
Figure 3. Relationship between receptive field size and retinal eccentricity in areas VP (dots) and ventral V2 (crosses). Each symbol represents a single unit. The ordinate values (square root of area in degrees) are derived from measurements of the minimal response field of single units as plotted by hand. The straight lines (VP, solid; $\mathrm{V} 2$, dashed) were fitted with the method of least squares. senting the horizontal meridian, and hence the anterior border of V2 (see also Gattass et al., 1981; Newsome et al., 1986; Van Essen et al., 1986).

Figure 2 uses the same format to show results from another hemisphere, in which the recordings were concentrated in VP. Because of the angle of the recording chamber used for this hemisphere, the sectioning plane was oblique to all of the cardinal axes (Fig. 2, upper left; see Materials and Methods). Stippling on the section outlines and on the cortical map indicates regions of degeneration resulting from callosal transection (see Materials and Methods). Three recording sites from VP in the OTS are indicated in the 2 section outlines on the upper right and also on the 2-dimensional map of ventral extrastriate cortex (lower right). Recording site A (section 1), farthest from the strip of callosal inputs, had a receptive field on the horizontal meridian at $10^{\circ}$ eccentricity and was thus at the V2/VP border. It was assigned to VP on the basis of receptive field size (scc bclow). On the second section, $2 \mathrm{~mm}$ below section 1 , site $\mathrm{B}$ had an intermediate receptive field, and site $C$, just at the edge of a patch of callosal inputs, had a receptive field near the superior vertical meridian. This confirms the basic topographic organization for VP found by Newsome et al. (1980, 1986).

\section{Receptive field size}

It is obvious from Figures 1 and 2 that the receptive fields illustrated for VP are considerably larger than those for V2. That this is consistently the case is shown in Figure 3, which is a plot of receptive field size versus eccentricity for V2 (crosses) and VP (filled circles). The average field dimensions, calculated as the square root of receptive field area, are almost twice as large for VP (mean, $4.8 \pm 1.2^{\circ} \mathrm{SD}$ ). The difference is highly significant $(p<0.001)$, and there is virtually no overlap between the populations when plotted as a function of eccentricity. The dependence of field size on eccentricity is slightly greater for VP than for V2, as indicated by the slopes of the regression lines (VP: 0.19 vs V2: 0.11). Gattass et al. (1981) reported a similar slope for the relationship between receptive field size and eccentricity for V1 but a much steeper slope for V2 (0.40).

\section{Functional properties}

Our exploration of functional organization in VP and ventral V2 was guided by the strategy of probing each single unit encountered for its selectivity to a variety of basic stimulus parameters. To illustrate this approach we will first discuss the types of response curves obtained from 1 unit in each area. The particular examples chosen showed highly selective responses for several different parameters, although this was a characteristic of only a minority of cells in either area.

Figure 4 shows the responses of a V2 cell to tests of direction, speed, disparity, and color selectivity. The lower part of each panel shows poststimulus time histograms of the response to each setting of the parameter being varied. The upper part shows the average response to either 3 or 5 repetitions of the stimulus, along with error bars indicating the SE. Figure $4 A$ illustrated the unit's average response to a slit of light moving in various directions across the receptive field. The polar plot above displays the average response to 12 directions of movement; this unit clearly preferred upward movements $\left(0^{\circ}, 30^{\circ}\right)$, with essentially no response to downward movement $\left(120^{\circ}-240^{\circ}\right)$.

As shown in Figure $4 B$, the speed of stimulus motion was also an important parameter for this unit. The cell responded best at $16^{\circ}$ and $32 \% \mathrm{sec}$ and gave better than half-maximal response only over a 4-fold range of speeds.

Selectivity for binocular disparity was tested with slits or spots of light that simulated trajectories parallel to the frontal plane. Interleaved with the binocular stimuli were monocular stimuli, in which the images on the screen were identical, but a shutter was closed over one eye or the other. As shown in Figure $4 C$, the cell preferred stimuli at zero disparity, i.e., on the plane of fixation. Stimulation with light bars that appeared farther away or closer to the animal (negative or positive disparity, respectively) elicited smaller responses, approaching the size of the monocular response at disparities of $\pm 2^{\circ}$. The monocular responses were weak, and the binocular response at zero disparity showed considerable facilitation over the monocular responses. Units with such behavior have been classified as tuned excitatory (Maunsell and Van Essen, 1983b; Poggio and Fischer, 1977). The disparity tuning in this cell was relatively broad.

The response to monochromatic stimuli was vigorous in the 


\section{V2 CELL}

\section{A DIRECTION}
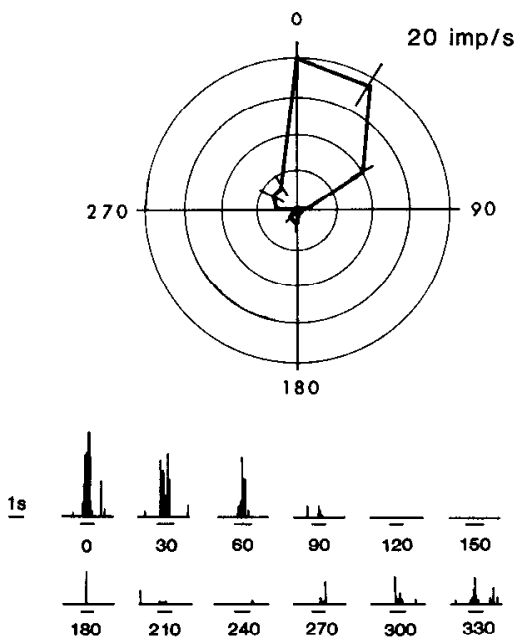

\section{B SPEED}
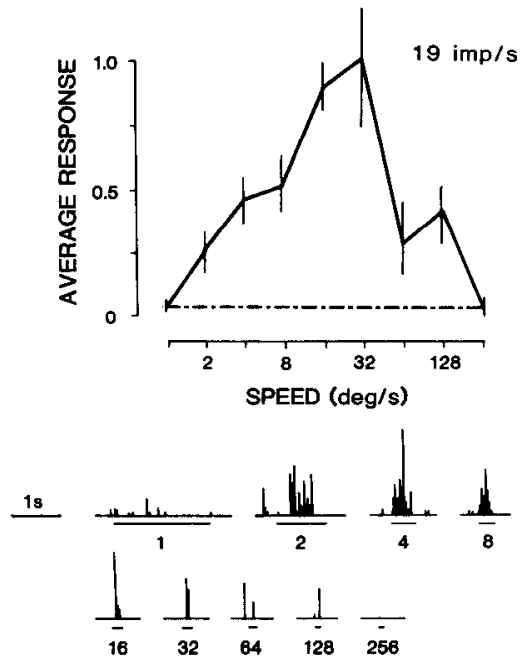

\section{DISPARITY}
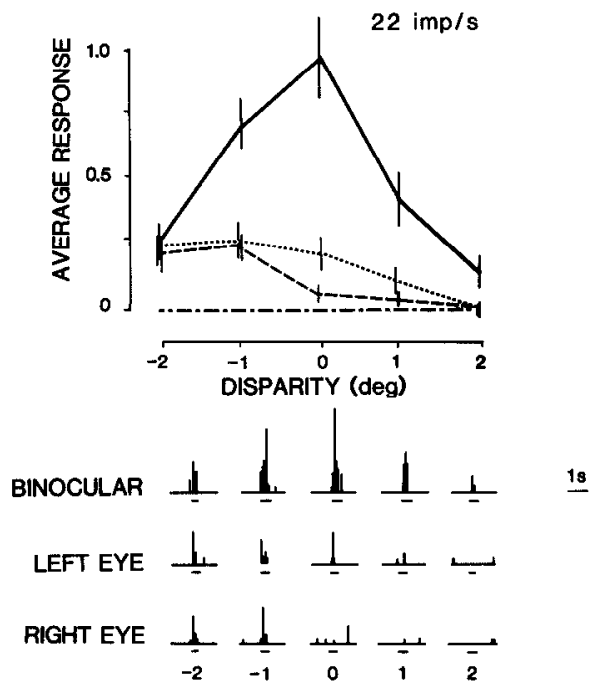

D COLOR
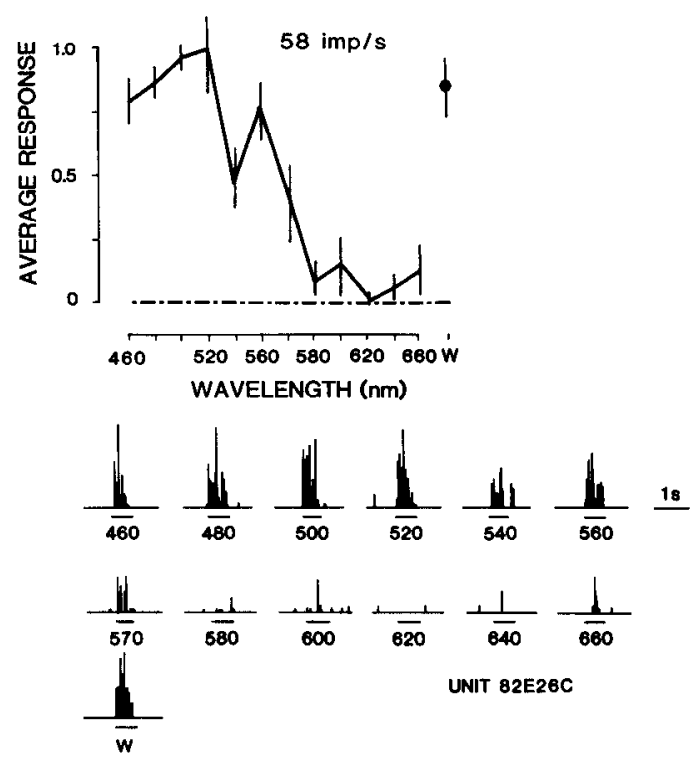

Figure 4. Responses of a single cell recorded in ventral V2 and tested for selectivity to direction $(A)$, speed $(B)$, binocular disparity $(C)$, and color $(D)$. The response field, $3^{\circ}$ across, was located in the upper visual quadrant halfway between the vertical and the horizontal meridians at $25^{\circ}$ eccentricity. For each parameter, the average rate of firing during 3-5 presentations of a bar or spot of light and the summed response histograms are shown. Vertical bars indicate \pm SEM; horizontal bars below each histogram, the time during which the stimulus was on. Curves are normalized to their respective maximum responses, shown alongside each plot. $A$, Polar plot of the cell's responses to a white bar moving in each of 12 directions, showing a strong preference for upward movements and very little responsiveness to movements in the opposite direction. $B$, The same cell was also tuned to the speed of stimulus motion. The interrupted line indicates the average background rate of firing. $C$, Solid line indicates the average binocular response to stimuli with different fixed disparities. Negative (uncrossed) disparities simulate stimuli appearing behind the fixation plane (far); positive (crossed) disparities indicate stimuli in front of the fixation plane (near). Dotted and dashed lines indicate the average monocular responses, which were above the average background rate of firing (interrupted lines) but small relative to the maximal binocular response. The stimulus, $2^{\circ}$ wide and moving vertically, remained at least partially within the $3^{\circ}$ receptive field at all disparities tested. $D$, The cell's response profile to narrow-band lights of equal photopic luminosity and to white light $(W)$ matched for equal luminosity. Actual transmission peaks for the 12 narrow-band filters used in these experiments were $459,478,501,518,538,558,573,581,600,624,640$, and $660 \mathrm{~nm}$. 


\section{VP CELL}

\section{A DIRECTION}

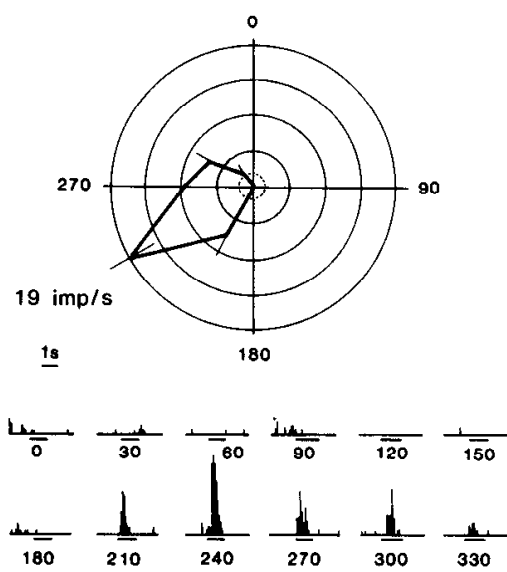

\section{B DISPARITY}
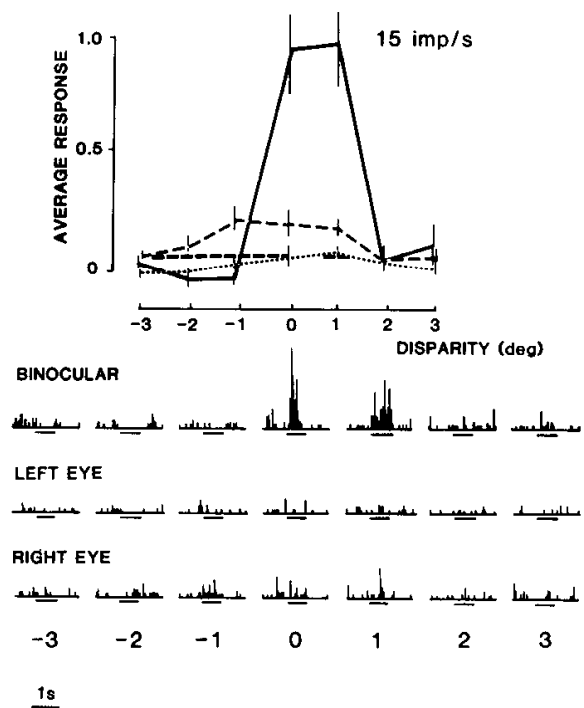

C COLOR

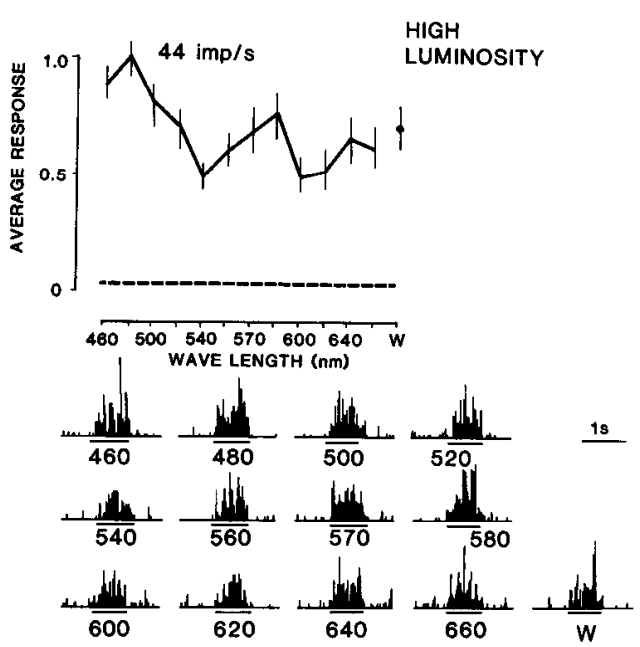

D

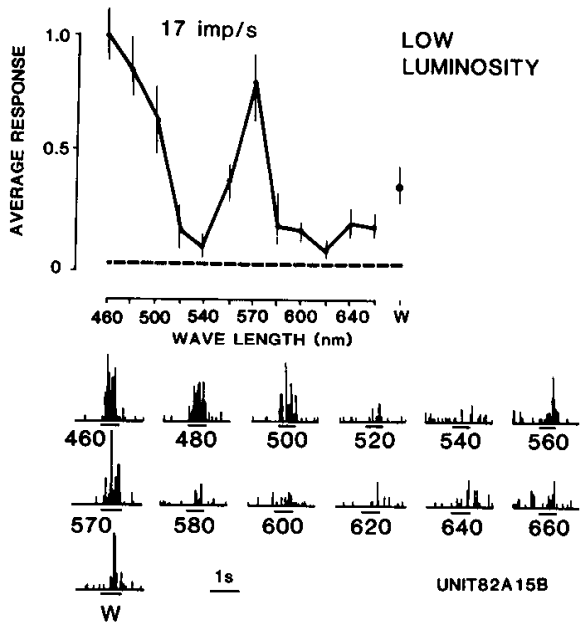

Figure 5. Average responses of a single cell recorded in VP and tested for direction $(A)$, binocular disparity $(B)$, and color $(C, D)$ selectivity. The receptive field, $5^{\circ}$ in diameter, was located in the superior visual quadrant near the horizontal meridian at $9^{\circ}$ eccentricity. Average ratc of firing and summed response histograms are presented in the format explained in Figure 4. This cell was not tested quantitatively for stimulus speed.

short and middle part of the spectrum (violet, blue, and green) but was progressively weaker at longer wavelengths (Fig. $4 D$ ). Despite this obvious color selectivity, though, white light was nearly as effective as blue light of equal photopic luminosity. It is noteworthy that the responses to white light in the color series were about twice as large as the peak responses in the preceding 3 series. This was still true at $1 \log$ unit lower luminosity. We attribute it to a change in the general level of excitability from one series to the next. Such changes, which were occasionally encountered in other cells as well, emphasize the importance of randomly interleaved stimuli when testing the selectivity for any given parameter.

The response curves shown in Figure 5 were recorded from a unit in VP that showed selectivity for direction, disparity, and, at low intensities, stimulus wavelength. Figure $5 \mathrm{~A}$ represents the average response to different directions in a plot similar to
Figure $4 A$. The preferred direction was down and to the left $\left(240^{\circ}\right)$, and movements in the null direction inhibited the cell's response, as indicated by a discharge rate lower than the background activity (dotted circle).

As illustrated in Figure $5 B$, there was a convergent input to this cell from both eyes, eliciting a vigorous response for disparities of $0^{\circ}$ or $+1^{\circ}$. Once again, the monocular responses were weak, and the best binocular response was much greater than the summed monocular responses.

This cell was also color selective, but it was chosen to illustrate several types of complexity that were sometimes found in chromatic properties. In this instance, the degree of selectivity was strongly dependent on stimulus luminosity; moreover, the selectivity, when present, involved more than one response peak. At high luminosity ( 200 trolands above background), the cell responded well to colored stimuli at all wavelengths, although 
A

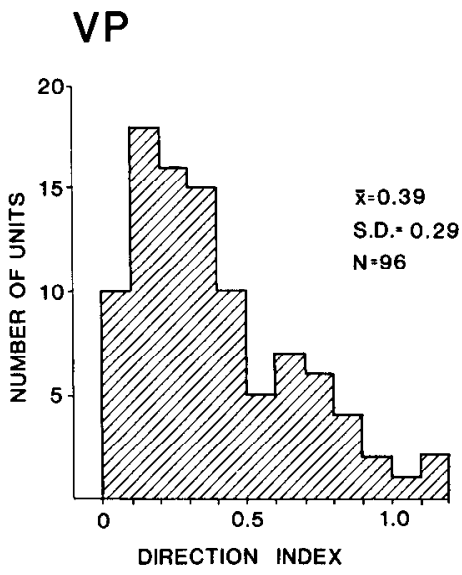
Figure 6. Comparison of the aver-
age directional responses in $\operatorname{VP}(A, C)$ and ventral V2 $(B, D)$. $A$ and $B$, Direction index (DI) reflects the relative responses to stimulus motion in the preferred and the null directions: $\mathrm{DI}=$ 1 - (Null - B)/(Best - B) where Best and Null denote responses to stimuli in preferred and null directions, respectively, and $B$ denotes background activity. Omni- and bidirectional cells thus have an index near zero. Cells with no response in the opposite direction have an index of 1 , and cells inhibited in the opposite direction have indices greater than unity. $C$ and $D$, Average, normalized direction tuning curves for $96 \mathrm{VP}$ units $(C)$ and $54 \mathrm{~V} 2$ units $(D)$. The tuning curve of each unit was normalized to its peak response and rotated to bring the peak to the top. The corresponding values from all the curves were then averaged. Bars, SD for each point; dashed line, the average normalized background rate of firing.
B

\section{V2}
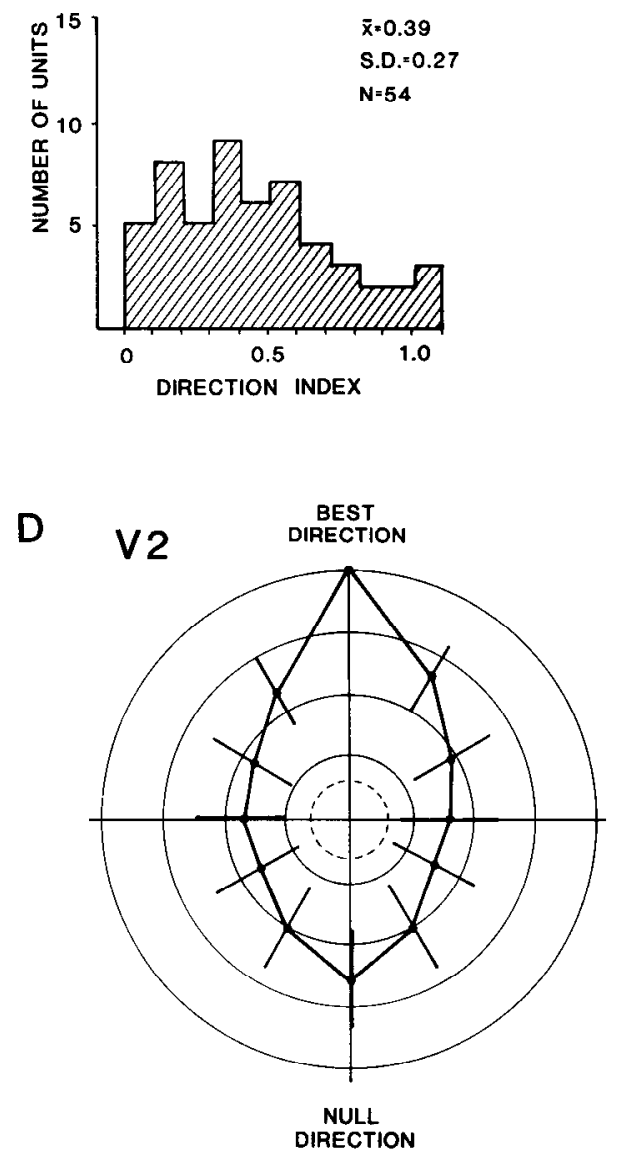

the response to blue $(480 \mathrm{~nm})$ and orange $(580 \mathrm{~nm})$ was significantly greater than that to green $(540 \mathrm{~nm})$ (Fig. $5 \mathrm{C})$. The degree of selectivity improved remarkably, however, when $0.6 \log$ unit dimmer stimuli (50 trolands above background) were used. The response curve now showed 2 clear peaks, with maxima in the blue $(460 \mathrm{~nm})$ and yellow $(570 \mathrm{~nm})$ portions of the spectrum. A weak response was observed to green $(520,540 \mathrm{~nm})$, orangered $(580,600 \mathrm{~nm})$, and white stimuli, which barely exceeded background activity (Fig. $5 D$ ). This change in spectral tuning was accompanied by a marked decrease in maximal firing rate. Interestingly, the well-tuned chromatic response was obtained when the unit operated in a similar dynamic range of firing (17.6 impulses/sec) as during the tests for directionality (19.6 impulses/sec) and binocular disparity (15.4 impulses/sec) obtained with white stimuli.

It is clear from these 2 illustrations that selectivity for a variety of stimulus parameters is present in both V2 and VP. In order to obtain general conclusions relevant to the overall function of these areas, we felt it important to study a large population of cells tested and quantitatively analyzed for as many types of selectivity as was practical. An important part of the analysis of most parameters was the calculation of an index for selectivity, which provides an objective measure of the degree of specificity of the neural response ( $c f$. Baker et al., 1981; Maunsell and Van Essen, 1983a). Each index, calculated from the response profiles to a given test series, compares the best response to some other response, either the overall worst or a value from some fixed setting relative to the best (e.g., opposite to the best response for assessing direction selectivity). The index was then calculated according to the gencral formula "Selectivity index" $=1$ - other/best, where responses are expressed relative to the spontaneous background. Thus, an index value of zero indicates a completely nonselective response, a value of 1 indicates no response to the other stimulus, and a value greater than 1 indicates a cell that is inhibited by the other stimulus. In this study a value of 0.7 was chosen as the cutoff for strong selectivity, which corresponds to a ratio of 3.3 between the best and the other response. A cell with a selectivity index of 0.5 (2-fold better response to the best vs the other stimulus) was considered to have a biased response.

\section{Direction}

Ninety-six units in VP and 54 units in V2 were tested for selectivity to the direction of stimulus motion. The incidence of direction-selective cells was low in both areas. Some cells, however, displayed remarkably sharp direction selectivity, as was illustrated in Figures $4 A$ and $5 A$. As alluded to in the preceding paragraph, this was quantitatively assessed with the "direction index" (DI), which compares the responses in the best and the opposite (null) direction (see figure legend). The DIs calculated for the 2 cells shown in Figures $4 A$ and $5 A$ were 0.89 and 1.04, respectively, reflecting the fact that they were both strongly direction selective. However, the overall distribution of DIs for VP and V2 showed a preponderance of cells with low values, 
A
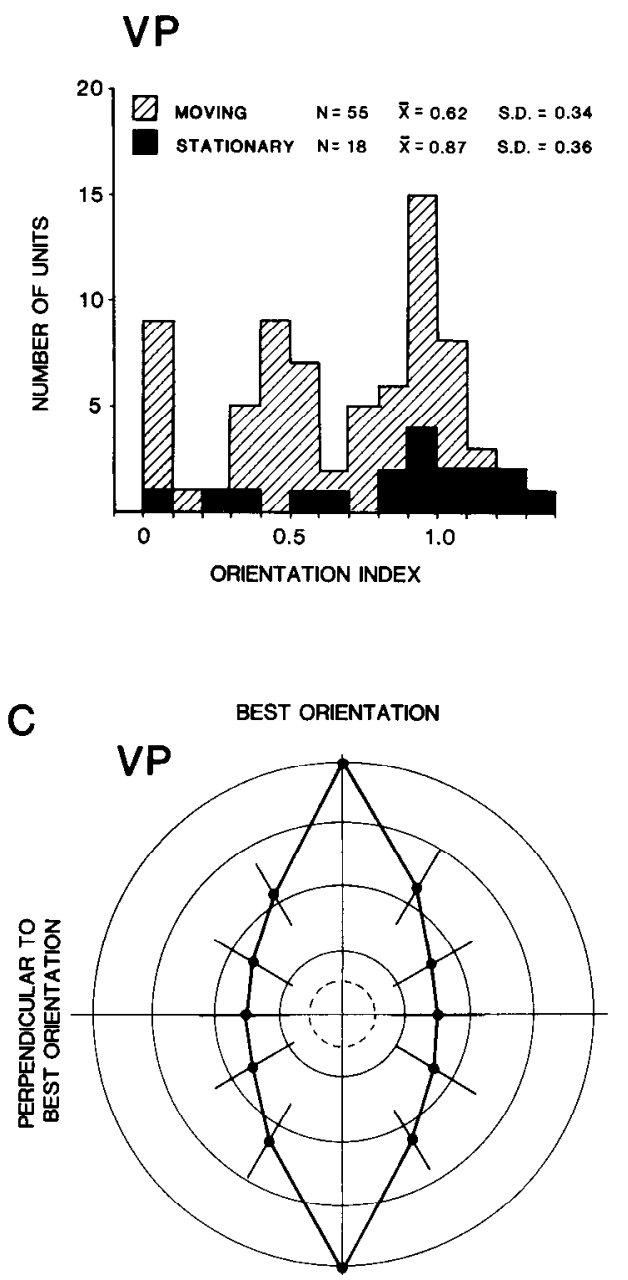

B

\section{V2}
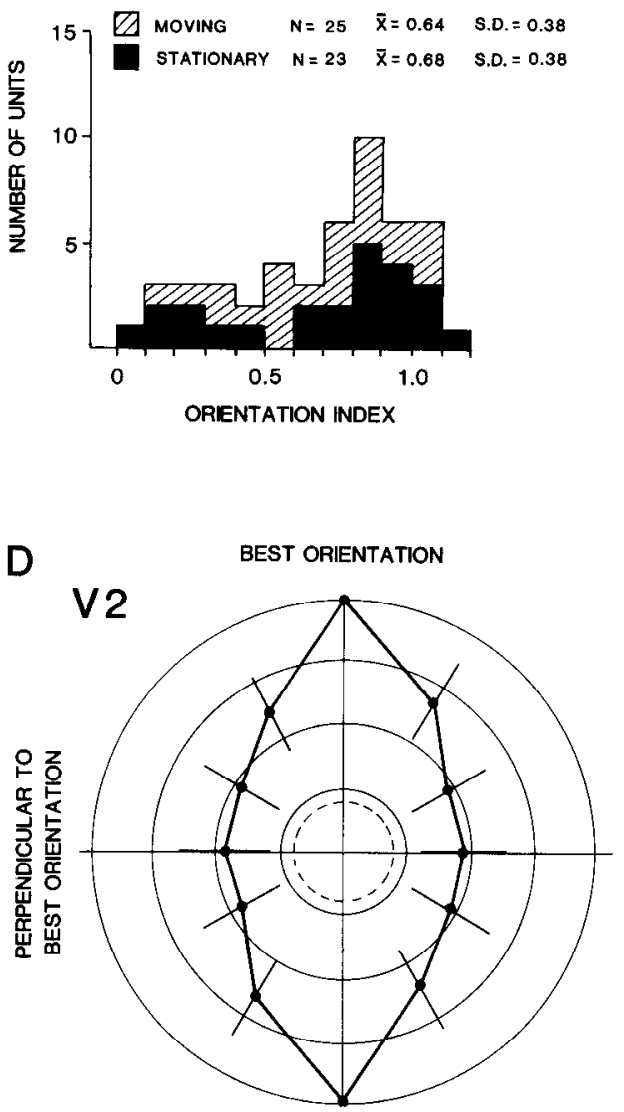

Figure 7. Comparison of orientation selectivity in VP $(A, C)$ and ventral V2 $(B, D)$ tested with stationary (solid columns) or moving (hatched columns) light bars (see text for further explanations). $A$ and $B$, The orientation index (OI) compares the relative responses in the preferred (Best) orientation and the orthogonal (Orth) orientation: $\mathrm{OI}=1-(\mathrm{Orth}-\mathrm{B}) /$ (Best - B), where B denotes background activity. The mean valucs in VP and V2 indicate that the average response to the best orientation is nearly 3 times that to the perpendicular orientation. Each entry on the histogram is represented in solid color if a test with flashed, stationary bars was made. Otherwise, the entry is included and shown by hatching if the direction index was less than 0.5. Hatched and solid entries are nonoverlapping, so that the overall profile represents the combined population. Comparisons of OI determined by applying both measures (stationary and moving) on the same cells revealed a good correlation on a cell-by-cell basis and no systematic differences overall (mean indices: 0.58 vs 0.59 for 12 V2 cells and 0.74 vs 0.69 for 11 VP cells; $p>0.4$ for both sets). $C$ and $D$, Average normalized orientation tuning curves for $73 \mathrm{VP}$ units $(C)$ and $48 \mathrm{~V} 2$ units $(D)$. The tuning curve of each unit was normalized to its peak response and rotated to bring the peak to the top. The corresponding values for all curves were then averaged. Bars, SD for each point; dashed line, the averaged normalized background rate of firing. corresponding to little or no direction selectivity, as illustrated in Figure $6, A$ and $B$. The 2 distributions are similar, with identical mean values for VP and V2 (0.39). In neither casc arc there multiple peaks in the histogram that would suggest welldefined classes according to directionality. Direction selectivity $(\mathrm{DI} \geq 0.7)$ was found in only $13 \%(13 / 96)$ of VP cells and $19 \%$ $(10 / 54)$ of V2 neurons. Direction bias $(0.5 \leq \mathrm{DI}<0.7)$ was found in an additional $15 \%(15 / 96)$ of VP cells and in $19 \%(11 /$ 54) of V2 cells.

Average tuning curves were generated in order to estimate the sharpness of direction selectivity in each area. Polar plots of these curves are shown in Figure $6 C$ (VP) and $6 D$ (V2). The curves were produced by normalizing each of the tuning curves to their best responses, rotating the curves to bring the best direction of movement to the top, and then averaging the normalized responses for each of the 12 points. In both VP and V2 the average response above background in the null direction was about half of the best response. For comparison, in MT the response in the null direction is only $9 \%$ of the maximal response (Maunsell and Van Essen, 1983a). Instead, the least effective direction in VP and V2 was orthogonal to the preferred direction.

\section{Orientation}

Data about orientation selectivity were obtained in 2 different ways. Some units (18 in VP, 23 in V2) were tested with stationary slits, flashed in the receptive field at 6 different orien- tations $30^{\circ}$ apart. Others were evaluated with the information obtained in the aforementioned direction series, in which a slit was moved along the axis perpendicular to its length. Testing with stationary bars provides an unequivocal measure of the unit's orientation selectivity (as long as the stimulus is properly centered in the receptive field), but testing with moving bars does not, because of the possibility that a cell can spuriously appear to be orientation selective just because it is dircction selective. We therefore excluded cells with a directional bias or selectivity (DI $\geq 0.5$ ) unless they had been tested with stationary stimuli. For the remaining cells we calculated an orientation index, which compares the responses to the best orientation to the orientation orthogonal to the best. The distribution of orientation indices is shown in Figure $7 A$ for 73 units in VP (solid bars, tested with stationary stimuli; hatched bars, tested with moving stimuli) and in Figure $7 B$ for 48 units in V2. The solid and hatched histograms in Figure $7 A$ have similar distributions, signifying that indices derived from tests with moving stimulus bars provide a reasonable measure of orientation selectivity in the population. A majority of units in VP $(42 / 73,57 \%)$ and in V2 $(29 / 48,60 \%)$ were clearly orientation selective, with an index $\mathrm{OI} \geq 0.7$. The percentage of cells with at least an orientation bias $(\mathrm{OI}>0.5)$ was $73 \%$ in both VP and V2. The distribution of orientation indices in VP shows 3 peaks, suggesting a grouping of cells according to their orientation selectivity. However, no corresponding groups are evident in the population tested with stationary stimuli in VP, nor in the overall distribution for V2. 
A

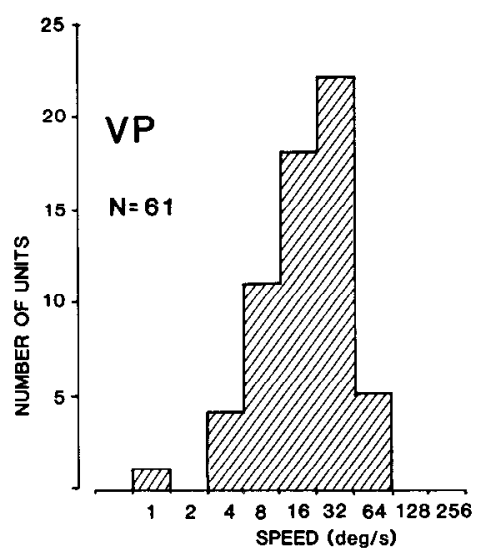

C

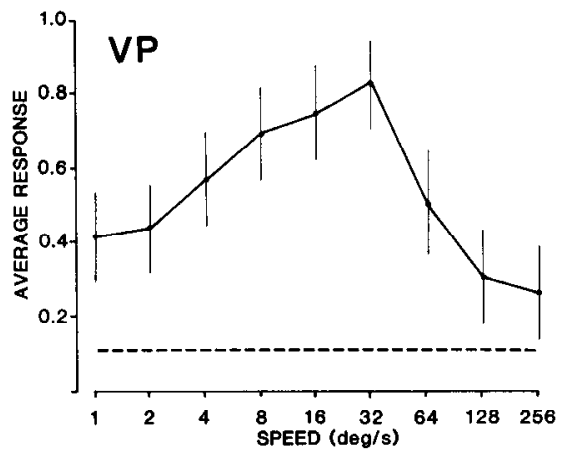

Figure 8. $A$ and $B$, Distribution of preferred speed in VP $(A)$ and ventral V2 $(B) . C$ and $D$, Average normalized response of 61 VP units $(C)$ and 13 V2 units $(D)$ to motion in the preferred direction and tested at speeds from $1^{\circ}$ to $256 \%$ sec. Bars, SD; dashed lines, the average normalized background rate of firing. $E$ and $F, A v-$ erage normalized speed tuning curves. The tuning curves of 61 VP units $(E)$ and $13 \mathrm{~V} 2(F)$ units were normalized to their peak rate of firing, superimposed, and points averaged. Bars, SD; dashed lines, the normalized average background rate of firing.
$E$

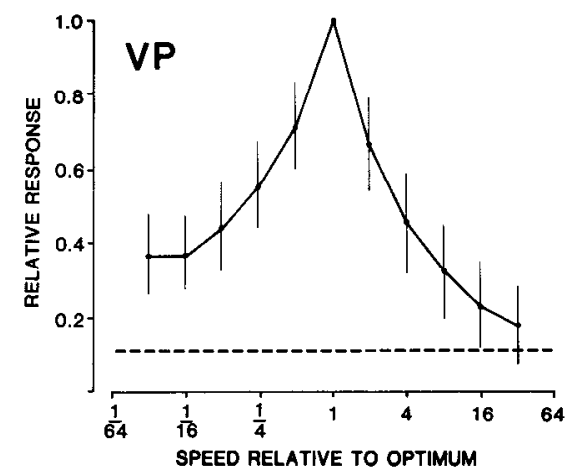

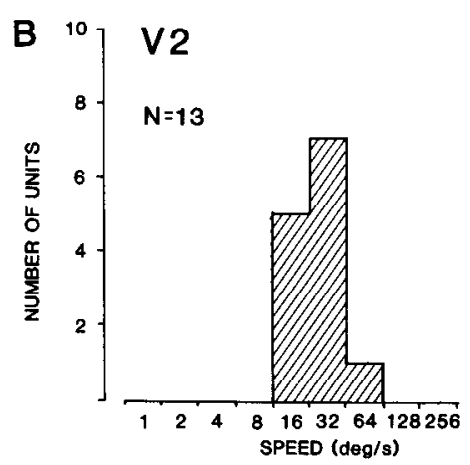
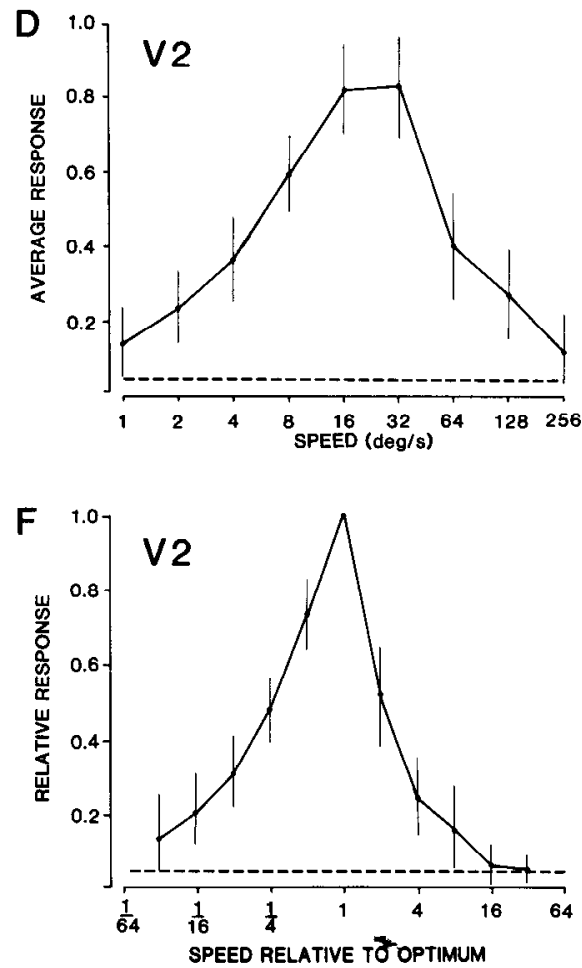

The average orientation index is similar for the 2 areas (VP, $0.68 \pm 0.36 ; \mathrm{V} 2,0.66 \pm 0.3$ )

The average orientation tuning for both areas is shown in Figure 7, $C$ and $D$. These curves were obtained by rotating the individual tuning curves, aligning and averaging their peaks. The average curve for VP is slightly narrower than for V2.

\section{Speed}

The selectivity for the speed of stimulus motion was examined quantitatively in 61 units in VP and 13 units in V2. (The sample size in V2 is small because systematic testing for speed tuning was not initiated until midway through the study, at which time most of the V2 recordings had already been obtained.) The testing was done with a stimulus bar of optimal length and width moved across the receptive field orthogonal to the best direction, at speeds between $1^{\circ}$ and $256^{\circ} / \mathrm{sec}$. Responses were measured as mean rate of firing rather than counting the total number of spikes during stimulus presentation (Orban et al., 1981), for reasons discussed by Maunsell and Van Essen (1983a). Without exception, cells in VP and V2 responded well to only a limited range of speeds ( $c f$. Fig. $4 B$ ).
Figure $8, A$ and $B$, shows the distribution of preferred speed in VP and V2, respectively. Both distributions are quite similar. They show a single peak at $32 \% \mathrm{sec}$, with a few cells preferring faster speeds. This is identical to the modal value found in MT (Maunsell and Van Essen, 1983a) but larger than the modal value $(8 \% \mathrm{sec})$ for V1 (see Fig. 9, Van Essen, 1985). On the other hand, the preferred speeds are more tightly clustered in VP and V2 than in MT and are similar in this respect to V1. Cells whose receptive fields were located more peripherally on average preferred faster stimulus velocities. From the quantitative analysis, we estimate that the average preferred speed in VP is 2 times greater at $20^{\circ}$ eccentricity than at $10^{\circ}$.

To illustrate the response of the overall population of cells to different speeds, we generated average response curves for VP and V2, as shown in Figure 8,C and $D$. The curves were produced by averaging individual normalized response curves and plotting the mean values on a logarithmic scale between $1^{\circ}$ and $256 \% \mathrm{sec}$. As expected from the distribution of preferred speeds, both curves peak at $32 \% \mathrm{sec}$. The range of effective speeds is similar in both areas. Both curves are slightly asymmetrical, with a steep slope to the right and a shallow slope to the left of 
the peak. They differ only in minor respects from the average response curve for MT (Maunsell and Van Essen, 1983a).

The curves shown in Figure 8, $E$ and $F$, illustrate the average tuning curve for cells in VP and V2, obtained by first shifting the normalized response curves so that their peaks superimpose, and then averaging them. The average tuning curve is slightly asymmetrical, indicating greater sensitivity for changes in speed on the high side of the peak. The average tuning curve is wider for VP than for V2 and MT. This is indicated by a full-width at half-peak (relative to background) equivalent to an 11-fold change of speed as compared to a 6.9-fold change in V2 and a 7.7-fold change reported for MT (Maunsell and Van Essen, 1983a). It is noteworthy that cells showing inhibition at speeds well away from the optimum were absent in VP and V2, even though such cells are common in MT. This may be related to the fact that the average level of spontaneous background activity was a smaller percentage of the peak responses in V2 and VP (5-10\%) than was reported for MT (20\%).

\section{Length}

In a small sample of cells (VP, 23; V2, 21) we looked at the effects of slit length on the neuronal responses. In these tests, random sequences of slits of various lengths at optimal width were presented at increments of $0.5^{\circ}-1^{\circ}$. In the great majority of cells, changes in slit length markedly influenced the response (VP, 82\%; V2, 86\%). In most cells in both areas the optimal length equaled or exceeded the length of the manually plotted excitatory receptive field. More than two-thirds of these cells exhibited orientation selectivity, and the effects of slit length could be attributed to summation along the axis of preferred orientation within the receptive field. About a third (29\%) of the V2 neurons, but only $13 \%$ of the VP cells, showed endstopping, in that they preferred slits with a length of less than three-quarters of the receptive field diameter. Less than half of these cells were orientation selective.

\section{Disparity}

Binocular parallax creates horizontal disparities between the retinal images that can be used as neuronal signals of distance from the fixation plane (Barlow et al., 1967). Disparity-selective cells have been found in V1, dorsal V2, and MT in the macaque (Hubel and Wiesel, 1970; Maunsell and Van Essen, 1983b; Poggio and Fischer, 1977). We examined disparity selectivity in 68 units in VP and 40 units in ventral V2. Each cell was testcd with moving binocular stimuli that simulated frontoparallel motion or stationary images at various depths beyond or in front of the fixation plane (see Materials and Methods). Disparity usually was changed at 10 intervals over the range from $-3^{\circ}$ to $+3^{\circ}$. Since this was a significant fraction of receptive field size, monocular responses were usually determined for each of the trajectories used in simulating the depth stimuli.

We found that a large majority of cells in VP $(60 / 62,97 \%)$ and in V2 $(20 / 21,95 \%)$ received excitatory binocular inputs that were reasonably balanced between the 2 eyes. This is illustrated in the ocular dominance histograms (Fig. 9, $A, B$ ) derived quantitatively from the comparison of the maximal firing rates after stimulation of the ipsi- and contralateral eyes. Most of the cells were classified in groups 3-5 (see figure legend). These results further support the notion that cells in extrastriate visual cortex are predominantly binocular (Baizer, 1982; Maunsell and Van Essen, 1983a; Poggio and Fischer, 1977; Zeki, 1978).

The response curves of individual disparity-tuned units in V2 and VP are shown in Figures $4 C$ and $5 B$. Both units were typical tuned excitatory units, responding only weakly to monocular stimulation through either eye and showing strong facilitation to binocular stimulation at or near zero disparity. Tuned excitatory units were the most common of the disparity-selec-

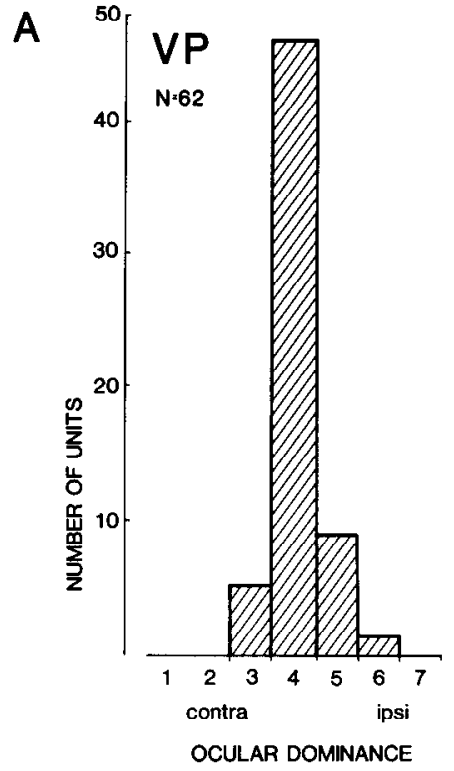

B

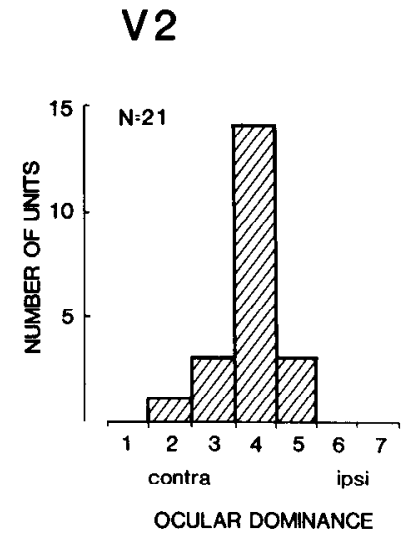

Figure 9. Distribution of ocular dominance for 62 VP units $(A)$ and 21 units in ventral V2 $(B)$. Classifications are derived quantitatively from the ratio of the monocular responses above background. Bins $I$ and 7 denote cells that were driven through 1 eye only, bins 2 and 6 contain cells for which the response to 1 eye was 3 or more times the response of the other, bins 3 and 5 contain cells for which the ratio of responses was between 1.5 and 3 , and bin 4 contains cells whose monocular responses were within a factor of 1.5 of one another.

tive units in both areas, constituting 24\% (16/68) of the VP sample and 33\% (13/40) of the V2 sample. The average response curves for the overall population of tuned excitatory cells in VP and V2 are shown in Figure $10, A$ and $B$, respectively. They were obtained by normalizing the monocular and binocular responses of each unit to the maximal binocular response and then averaging across units for each disparity. The shape of these curves is symmetrical around the peak at zero disparity. The slope is steepest near the optimum, indicative of a high sensitivity to changes in disparity close to the horopter. The peak binocular response is greater than the sum of the monocular responses above background, indicating strong facilitation at the optimal disparity. The tuning curves for some cells were considerably sharper than the average value, but even when tested at smaller intervals, none of the cells in our sample had tuning curves as sharp as those reported in the foveal striate cortex of awake, bchaving animals (Poggio and Fischer, 1977).

In VP, $25 \%(17 / 68)$ of the neurons, and a single cell in V2, showed asymmetrical response curves. The firing rate in these cells remained high over a broad range of disparities on one side of zero disparity. Neurons with this type of behavior, showing either good responses only to crossed disparitics (corrcsponding to stimuli near the animal) or only to uncrossed disparities (corresponding to stimuli beyond the horopter) were classified as "near" or "far" cells (Poggio and Fischer, 1977). In VP, 8 near cells (12\%) and 9 far cells (13\%) were encountered; their average response curves are shown in Figure $10, C$ (far) and $D$ (near). Both curves show strong responses at zero disparity but peak at disparities away from zero. Occasionally we found tuned inhibitory cells (VP, 3/68; V2, 1/40) that showed binocular inhibition to zero disparity (not illustrated).

About half of the cells examined did not show any form of selectivity to binocular disparity (VP: $32 / 68,47 \%$; V2: $25 / 40$, $62 \%$ ). The average response curves of these cells are shown in Figure $10, E$ and $F$. In each of the different conditions, the firing rate remained flat over the whole range of disparities. The bin- 
Figure 10. Averaged normalized response curves of VP and ventral V2 cells to stimuli with different fixed disparities moving in the preferred direction. Binocular response $(B)$, solid line; monocular response, left $(L$, dotted line) and right ( $R$, dashed line). $B a r s, \mathrm{SD}$; horizontal dashed lines, average normalized background rate of firing. $A$ and $B$, Average tuned excitatory responses of $16 \mathrm{VP}$ units $(A)$ and $13 \mathrm{~V} 2$ cells $(B)$. The peak binocular response is at zero disparity, indicating a preference for stimuli on or near the horopter. $C$, Average far response of 9 VP units that preferred uncrossed disparities. $D$, Average near response of 8 VP units that preferred crossed disparities. $E$ and $F$, Disparity nonselective VP cells $(E)$ and V2 cells $(F)$.
A

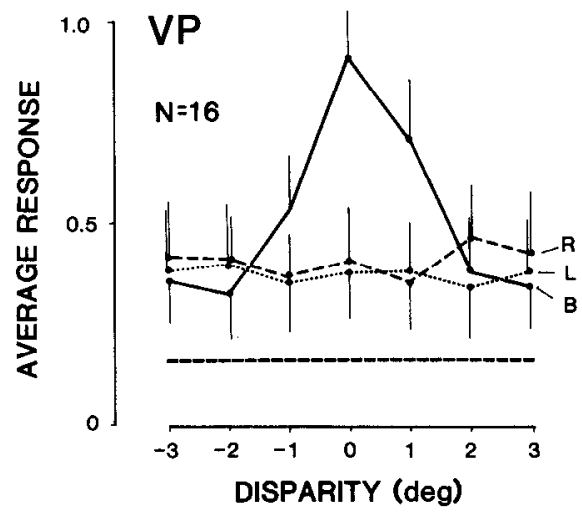

C

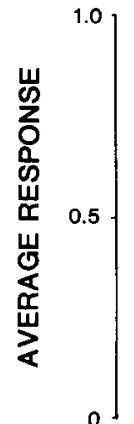

VP
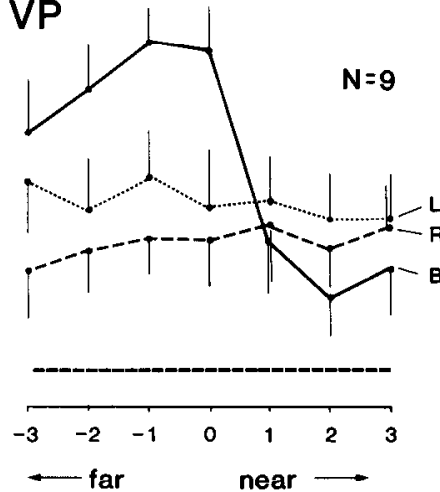

$E$

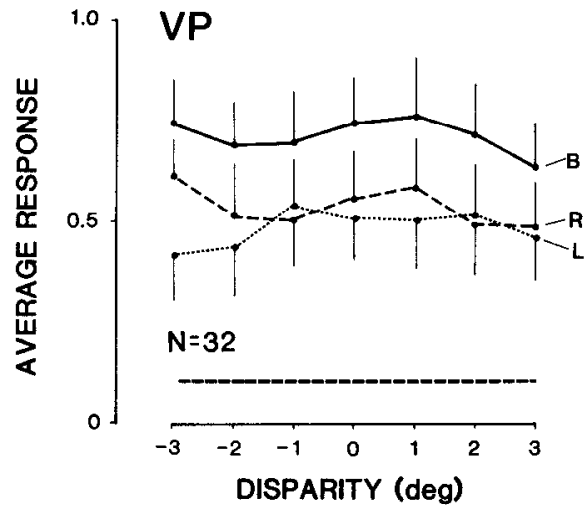

B

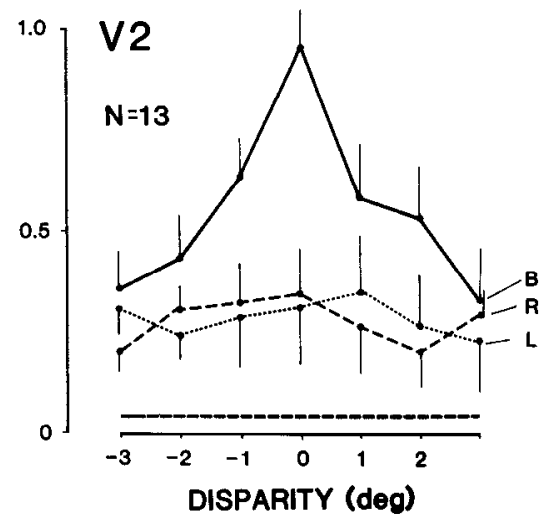

D

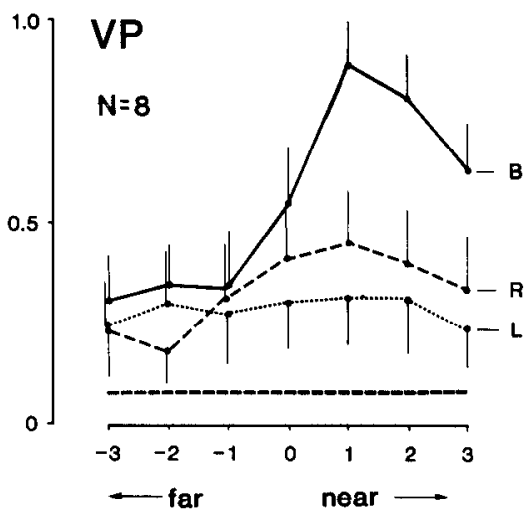

F

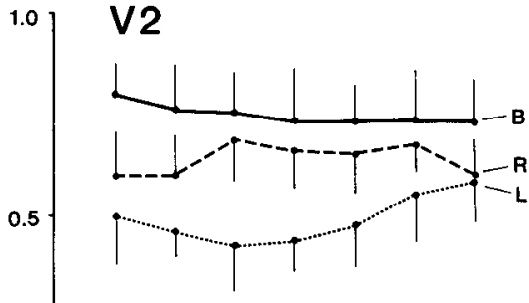

$\mathrm{N}=26$

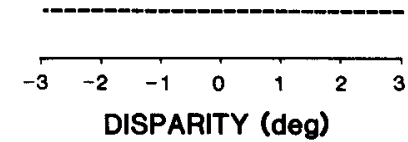

ocular response was only modestly larger than either monocular response. This contrasts with the monocular responses observed in disparity-selective cells, which were typically much smaller than the maximal binocular response.

\section{Color}

\section{Functional classification}

Eighty-one neurons in VP and 28 cells in ventral V2 were studied extensively for their selectivity to narrow-band (460-660 $\mathrm{nm}$ ) stimuli and white light of equal photopic luminosity. Testing routinely started out with a qualitative assessment of the cell's spectral requirements using broadband color filters (Wratten, Kodak) and manually controlled stimulation. In most cases $(70 \%)$, this description agreed with the subsequent quantitative assessment of the cell's color selectivity and its preferred wavelength(s). Of the cells that we failed to classify adequately, some preferred black stimuli, others displayed their selectivity only at lower stimulus luminosities, and still others had response curves with multiple peaks.

Once color selectivity was characterized, the spatial arrangement of the receptive field was briefly examined. Most cells had what appeared to be a uniform receptive field organization, without obvious spatially segregated subregions having different spectral selectivities. On rare occasions, however, we encountered cells whose spectral selectivity or On/Off excitatory response properties changed when stationary spots of different sizes were used. However, our data are not extensive or systematic enough to provide a detailed categorization of these aspects of receptive field organization in VP or V2. In most cases, we simply pursued quantitative testing using the optimal settings for orientation, direction, and speed worked out in the preceding tests. Stimulus depth was always fixed at zero disparity, however, thereby avoiding the use of crossed polarizing filters and the nondepolarizing screen, which unduly limited the photopic luminosity range of monochromatic stimuli and would have 

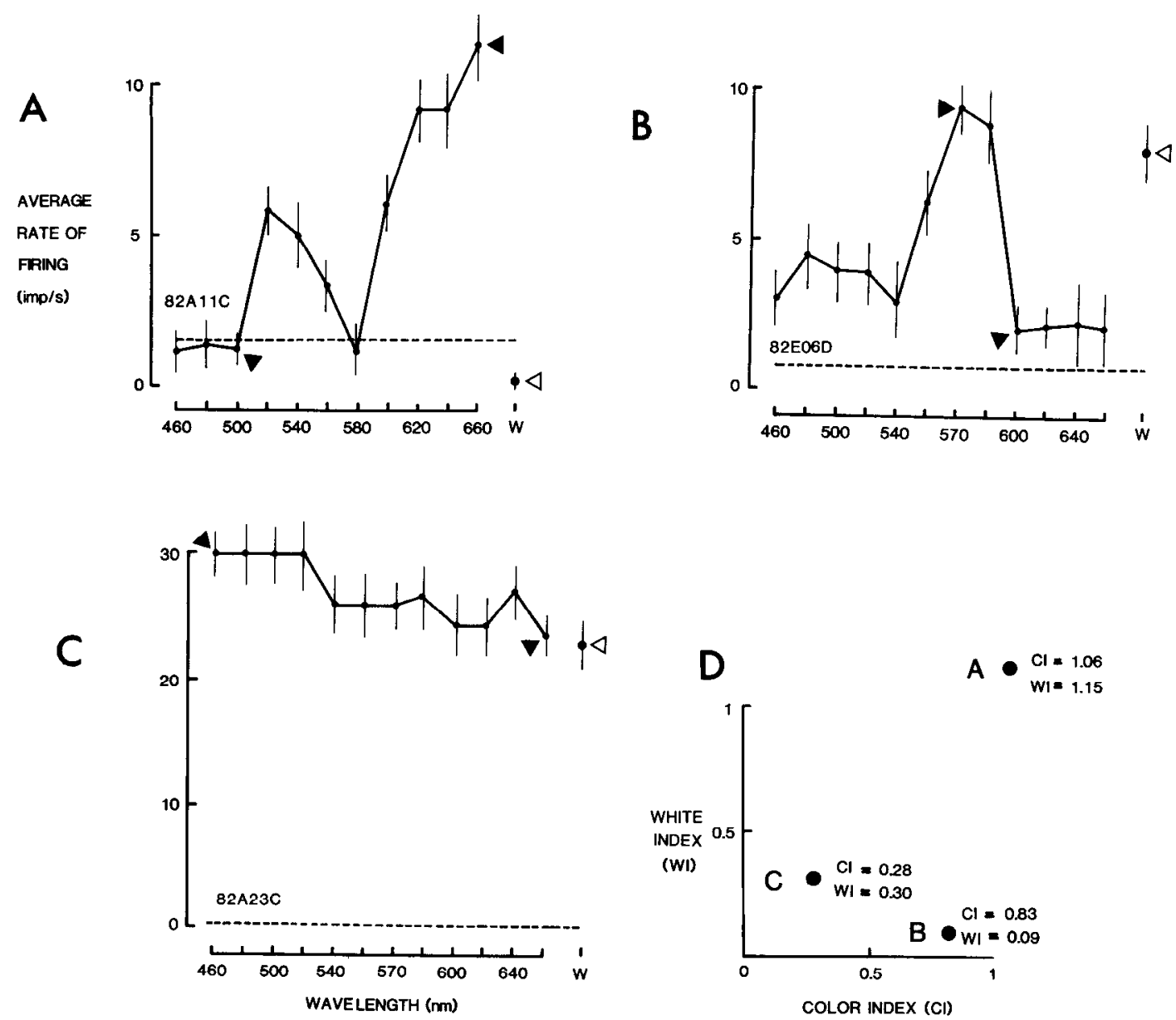

Figure 11. Quantitative assessment of the degree of wavelength selectivity. $A$, VP cell that responded well to some wavelengths (maximum: 660 $\mathrm{nm}$, solid arrow), showed little or no response to others (minimum: $500 \mathrm{~nm}$, solid arrow) and was inhibited by white light ( $W$, open arrow). Dashed line, the average background rate of firing. $B$, Response profile of a wavelength-selective VP unit that also responded well to white light. $C$, Response profile of a VP cell with flat spectral tuning and a large white response. $D$, Dual index plot (color index, CI, vs white index, WI) for cells $\mathrm{A}-\mathrm{C}$. $\mathrm{CI}=1-(\mathrm{Min}-\mathrm{B}) /(\mathrm{Max}-\mathrm{B}) ; \mathrm{WI}=1-(\mathrm{W}-\mathrm{B}) /(\mathrm{Max}-\mathrm{B})$, where $\mathrm{B}$ denotes background response and $\mathrm{W}$ denotes white response.

made it impossible to derive good action spectra. This did not pose a major difficulty, as the majority of cclls in both areas were tuned excitatory or not disparity selective (VP, 71\%; V2, $95 \%$ ), and most near or far cells responded well at zero disparity (Fig. 10, $C, D$ ).

The results from our quantitative analysis of color properties in V2 and VP confirmed the impression gained from the qualitative assessments, namely, that most cells had at least some color selectivity, but that the degree of selectivity varied over a wide range. The examples already illustrated include a cell that was strongly color selective but also responded well to white (Fig. $4 D$ ) and another cell that was strongly selective when stimuli were dim (Fig. 5D) but much less selective using brighter stimuli (Fig. 5C). Figure 11 illustrates 3 additional cells, the first of which was color selective and unresponsive to white (Fig. $11 \mathrm{~A})$, the second of which was also color selective but very responsive to white (Fig. $11 B$ ), and the third of which was completely nonselective (Fig. 11C). From inspection of a large number of such tuning curves it became apparent that no single measure would be adequate for describing the rich variety of color properties found in cortex. We, therefore, concentrated our analysis on 3 separate measures we believe provide a reasonable first-order characterization that could be applied to all the cells in our sample and that can serve as an objective basis for comparisons with other visual areas as well. One measure is the preferred wavelength among a full set of equal-luminosity stimuli. The other 2 measures are indices of the degree of selectivity: Onc, the color index (CI), compares responses to the best and worst monochromatic stimuli; the other, the white index (WI), compares responses to white and the best monochromatic stimulus. In both cases the indices are expressed in a fashion similar to the indices for directionality and orientation, with values of zero indicating no sclcctivity, unity indicating high selectivity, and greater than unity indicating inhibition to the worst stimulus (see Fig. $11 D$ and legend). The solid arrows in Figure $11, A-C$, indicate maximum and minimum chromatic responses, the open arrows the response to white, and the dashed lines the background activity. In order to provide a graphical description of color properties for a population of cells, we constructed dual-index plots of CI versus the WI. The indices for each of the 3 cells in Figure $11, A-C$, are shown on the dualindex plots in Figure $11 D$. The examples include high values for both indices $(A)$, indicating color selectivity and unresponsiveness to white; a high CI and low WI $(B)$, indicating color selectivity along with responsiveness to white; and low values for both indices $(C)$, indicating lack of selectivity by either criterion.

The results for the entire population of well-characterized cells in VP and V2 are shown in Figure 12. Each point represents the results from a single cell, with the different symbols explained below. It is evident at a glance that for $\mathrm{VP}$, the cells are distributed continuously over a broad range, from nonselective 

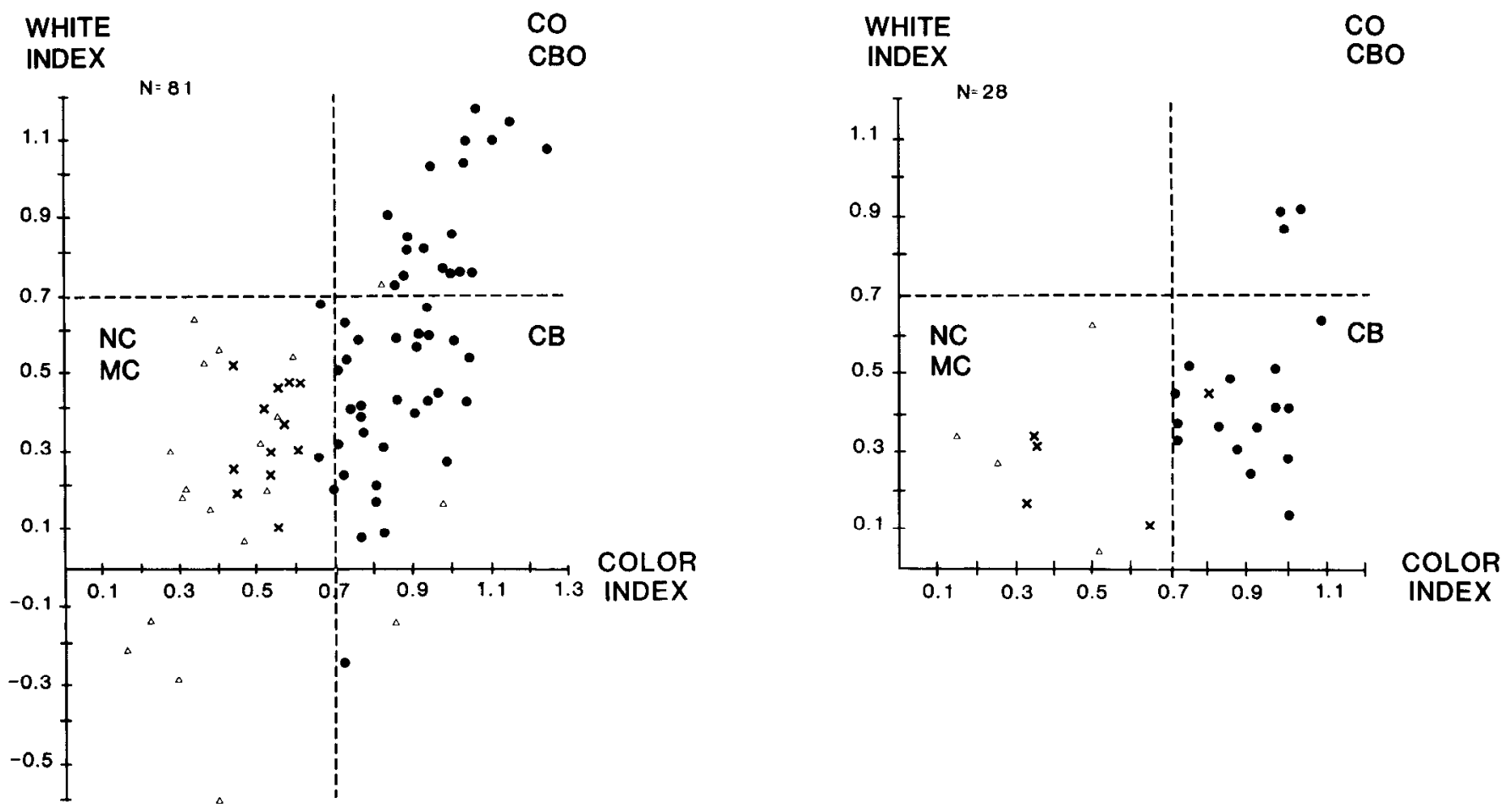

Figure 12. Distribution of color index (CI) and white index (WI) derived from 81 VP neurons $(A)$ and 28 cells in ventral V2 $(B)$ tested for wavelength selectivity. Each symbol corresponds to a single cell. Filled circles indicate units with a minimal separation between the average maximal and minimal spectral response of at least twice the sum of the SE. Crosses denote cells where the separation between the maximum and the minimum responses was equal to or less than twice the sum of SE but the error bars were nonoverlapping. For cells marked with open triangles, the error bars of the average maximum and minimum responses were overlapping. Dashed lines mark the $\mathrm{CI}=0.7$ and $\mathrm{WI}=0.7$ cutoff, which corresponds to a 3.3-fold difference between the best and the worst response. $N C$, noncolor; $M C$, marginal color; $C B$, color biased; $C B O$, color biased with opponency; $\mathrm{CO}$, color opponent (see text for definitions).

to highly selective along both axes, with no obvious clustering into well-defined subgroups or categories. In V2 there is a hint of clustering, but this may be related to the smaller sample size. (Most of our V2 recordings were done at an early stage of the project, when color tests were made using equal-intensity rather than equal-luminosity stimuli; CI from these early recordings are not included.) In both plots only a few cells have a CI below 0.3 , indicating that few spectral response curves are completely flat. This is largely attributable to inherent variability of the responses; the SE for each point in the response profiles of Figures 3, 4, and 11 signify that there were significant statistical fluctuations even to repetition of an identical stimulus.

Despite the lack of natural groupings in the color domain, it is nonetheless desirable to designate a level that represents a biologically significant degree of color selectivity. We chose to classify cells as color selective if they passed 2 independent criteria. The first is that the response to the preferred color should be different from that to the worst color by at least twice the sum of the SE for the 2 values. Units fulfilling this criterion are denoted with full circles in Figure 12. Marginally significant color tuning was diagnosed if the separation of the means was less than twice the sum of the SE but the error bars did not overlap; these units are depicted with crosses. Finally, open triangles symbolize units whose maximal and minimal color responses were not significantly different, as judged by overlapping error bars. The second criterion for color selectivity is that the CI should equal or exceed 0.7 . This value for the cutoff corresponds to a slightly greater than 3 -fold ratio between best and worst responses, a degree of tuning that is commonly ac- cepted as genuine selectivity when dealing with other parameters, such as orientation and direction (see above).

A clear majority of neurons in VP $(48 / 81,60 \%)$ and V2 (18/ $28,64 \%$ ) were color selective according to the criteria just describcd. The incidence of color-selective cells in both areas showed no obvious dependence on eccentricity over the range from $5^{\circ}$ to $25^{\circ}$.

Within the VP population, the WI varied continuously from one extreme, where the response to white was equal to or even better than the response to the preferred color (WI $\leq 0$ ), to the other extreme, where there was no response or even inhibition to white $(W I \geq 1)$. Once again, despite the lack of natural groupings, it is desirable to set a cutoff level of the WI that reflects a biologically significant degree of opponency between different cone inputs. We chose a value of 0.7 for the WI to distinguish between cells with strong opponency (WI $\geq 0.7$ ) and cells lacking strong opponency (WI $<0.7$ ). By combining the cutoffs for both the CI and WI, we then divided the dual-index graph into 4 domains. These domains were labeled in a manner similar to the scheme used by Schein et al. (1982) in their study of V4. On the basis of qualitatively assessed responses, they classified cells as color opponent, color biased, color biased with opponency, or nonselective for color. In our scheme, color-biased (CB) cells are those that are selective for stimulus wavelength (CI $>0.7$ ) but respond well to white (WI $<0.7$ ). Color-opponent (CO) cells are excited at some wavelengths, are inhibited (or give Off responses) at other wavelengths (CI $>1.0$ ), and are unresponsive to white (WI $\geq 1.0$ ). Color biased with opponency (CBO) cells respond well at some wavelengths and poorly at 

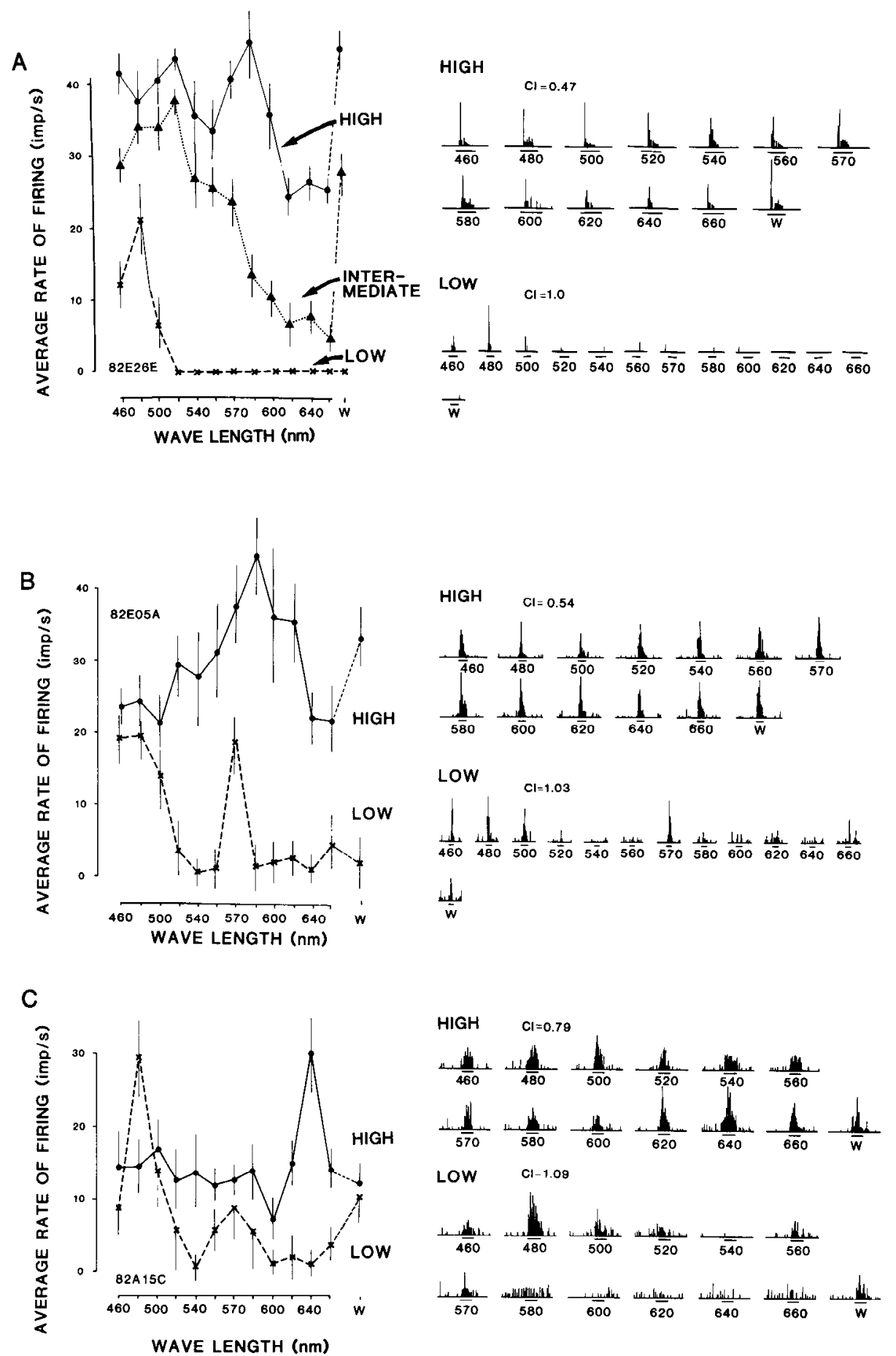

Figure 13. Luminosity dependence of spectral response profiles. Left, Average response curves to 5 repetitions at each luminosity (bars, SE). Right, Summed response histograms and corresponding color indices. $A$, Single unit in ventral V2. At maximum (High) luminosity (200 troland) spectral tuning was poor (filled circles) and not color selective $(\mathrm{CI}=0.47)$. At 0.5 $\log$ units attenuation (Intermediate, triangles), the cell was highly selective for short wavelengths, a property that was even more prominent at $1 \log$ unit attenuation (Low, crosses, $\mathrm{CI}=1.0$ ). $B$, Response curves of a VP unit that showed noncolor properties at high stimulus luminosity $(\mathrm{CI}=0.54)$. The same unit displayed a high degree of color selectivity $(\mathrm{CI}=1.03)$ to dimmer lights (Low: $0.6 \mathrm{log}$ units attenuation). $C, C B O$ unit in VP with marked preference to long wavelengths at high stimulus luminosity $(\mathrm{CI}=0.79)$. Its response peak shifted to short wavelengths at low luminosity $(0.6 \log$ units attenuation, $\mathrm{CI}=$ 1.09). others $(C I \geq 0.7)$ and respond poorly to white $(W I \geq 0.7)$. In short, $\mathrm{CO}$ cells have both $\mathrm{CI}$ and $\mathrm{WI}$ above 1.0; CBO cells have both indices above 0.7 but not both above 1.0; and $C B$ cells have a CI above 0.7 and a WI below 0.7 . There were only a few cells in our sample that were unambiguous $\mathrm{CO}$ cells, and for most of the remaining analysis they will be grouped with the larger number of CBO cells. Cells with a $\mathrm{CI}$ and WI less than 0.7 were designated as non-color selective (NC) or marginally color selective (MC). It is noteworthy that there were no cells in VP or V2 in the upper-left portion of the dual-index graphs in Figure 12 (low CI and high WI) that would correspond to responsiveness to all monochromatic stimuli but not to white. On the other hand, there were a few cells with the opposite kind of selectivity, responding to white better than to any monochromatic stimulus and thus having a negative WI. Only a single cell had a strong preference for white, though, with a WI of -0.6 . A few cells were encountered that responded well to black stimuli on a white background, but not to monochromatic stimuli or to colored cutouts on a white background. We were unable to quantify the degree of selectivity of these putative blackpreferring cells, however.

\section{Response curves at different luminosities}

The CI shown in Figure 12 were derived from stimuli at the maximal luminosity tested, which was usually 200 trolands, but was $0.3-0.6 \log$ units lower for some cells. It was of interest to 


\begin{tabular}{|c|c|c|c|c|}
\hline $\begin{array}{l}\text { Light } \\
\text { intensity }\end{array}$ & $\begin{array}{l}\text { Units tested } \\
\text { for color }\end{array}$ & $\begin{array}{l}\mathrm{NC}, \mathrm{MC} \\
(\%)\end{array}$ & $\begin{array}{l}C B \\
(\%)\end{array}$ & $\begin{array}{l}\mathrm{CO}, \mathrm{CBO} \\
(\%)\end{array}$ \\
\hline High & 81 & $\begin{array}{c}32 \\
(40)\end{array}$ & $\begin{array}{c}30 \\
(37)\end{array}$ & $\begin{array}{c}19 \\
(23)\end{array}$ \\
\hline Low & 45 & $\begin{array}{c}18 \\
(40)\end{array}$ & $\begin{array}{c}17 \\
(38)\end{array}$ & $\begin{array}{c}10 \\
(22)\end{array}$ \\
\hline
\end{tabular}

Spectral selectivity and classification into different groups were determined quantitatively (see text). The total numbers and precentages of cells in each class and at each luminosity are given. $\mathrm{NC}$, noncolor; $\mathrm{MC}$, marginal color; $\mathrm{CB}$, color biased; $\mathrm{CBO}$, color biased with opponency; $\mathrm{CO}$, color opponent.

know to what degree the response properties of a population of cells would depend on luminosity, as was shown for an individual cell in Figure 4. Forty-five cells in VP were studied at 2 or more luminosities separated by $0.4-1.0 \mathrm{log}$ unit attenuation. In the majority of cases ( 30 out of 45 ), there was no major change in the shape of the response curve; the responses were simply weaker at lower luminosity. In these cells the changes in CI were quite modest as long as the luminosity was well above threshold. The magnitude of the shift was 0.1 on average for $\mathrm{CI}$ and 0.18 for WI. The direction of the shift was not systematic, though; the mean CI was 0.81 at high luminosity and 0.86 at low luminosity, and the mean WI was 0.51 and 0.57 , respectively. This indicates that the spectral selectivity of the majority of color-selective cells remains largely unchanged within the luminosity range of 20-200 trolands above background.

A minority of cells in VP (10) and V2 (1) displayed more complex properties, namely, dimming of the stimulus caused a large change in color selectivity. In 7 cells, the response curves at high luminosity were relatively flat (CI: $0.54-0.61$ ), and 2 cells showed marginal color selectivity (CI: $0.71,0.77$ ). When the stimulus was attenuated, however, sharp spectral tuning $(\mathrm{CI}$ : 0.92-1.07) became apparent, and the cells responded only to a narrow band of wavelengths. Figure $13, A$ and $B$, illustrates 2 such examples. The unit shown in Figure $13 A$ was recorded in V2. At high stimulus luminosities the cell showed only broad spectral tuning (CI: 0.47 ). The response curve was much narrower at intermediate luminosities $(0.5 \mathrm{log}$ unit attenuation; $\mathrm{CI}$ : $0.86)$ and still narrower at low luminosities ( 1 log unit attenuation; CI: 1.0). Figure $13 B$ shows a VP unit with a similar behavior but with a more radical change in the overall shape of the response curve. The most striking difference was the presence at low luminosity of 2 response peaks (blue, yelloworange), and the loss of responsiveness to green and deep red colors. Another such example has already been illustratcd (Fig. $5, C, D$ ), in which a cell with marginal preferences for blue and an unconvincing preference for yellow-orange at high luminosity displayed a strong selectivity for blue (460-500 $\mathrm{nm}$ ) and yellow $(570 \mathrm{~nm})$ at low luminosity.

The most surprising property we encountered was an outright shift in preferred color, from a single peak at one wavelength to a single peak at a very different wavelength. This occurred in only 2 cells, 1 of which is illustrated in Figure $13 C$. At high luminosity there was a sharp peak in the red end of the spectrum $(640 \mathrm{~nm})$, which shifted to the blue end $(480 \mathrm{~nm})$ at low luminosity. Despite the dramatic difference in color selectivity, the discharge rate and amplitude of the action potentials remained stable, and we are reasonably confident that this was the same, well-isolated single unit, and not a sequential recording from 2 cells.

Given that the color properties of some cells are strongly luminance dependent, it is clearly important to assess the degree to which this affects the overall incidence of color selectivity as judged by our determinations of $\mathrm{CI}$. We found that about a third $(37 \%, 17 / 45)$ of the cells studied at 2 or more luminosities changed their basic designation as to color selectivity, with 10 going from marginally or non-color selective at high luminosity to color selective at low luminosity and 7 going in the opposite direction. Thus, at least in VP, there appears to be little net effect of stimulus luminosity on the estimated incidence of color selectivity. This is substantiated, as discussed previously, by the fact that cells judged to be color selective by quantitative analysis with monochromatic stimuli generally showed similar color preferences when examined qualitatively with Wratten filters that provided stimuli of even higher luminosity. On the other hand, there was an indication that the WI tended to shift to higher values (lower responsiveness to white) at low luminosities; 6 cells judged to be $C B$ at high intensities were designated $\mathrm{CO}$ or $\mathrm{CBO}$ at low luminosity. The percentage of cells assigned to each category, however, was very similar at high and low luminosity, as shown for VP in Table 1. In V2 only a few cells were tested at more than one luminosity. The percentage of $\mathrm{CB}$ cells in V2 was slightly higher $(54 \%, 15 / 28)$ than in VP, and the fraction of CO cells was slightly lower $(10 \%, 3 / 28)$. From these data we conclude that more than half of the cells in VP and V2 are color selective and that the luminosity of the test stimuli does not dramatically alter these estimates, although it may affect the degree of opponency inferred from the responsiveness to white.

From the various examples of response profiles obtained at different luminosities (Figs. 5, $C, D ; 13, A-C ; 16 A$ ), it is apparent that a large increase in luminosity may lead to an increase in the response at some wavelengths (relative to the maximal responses) and little or no increase at other wavelengths. In exceptional instances (Fig. 13C), the absolute magnitude of the response to the brighter stimulus may even be less than that to the dimmer stimulus. In other words, the slope of the response versus intensity function varies greatly with wavelength and is sometimes even negative. From this it follows that the response profile at suprathreshold luminosities cannot in general be predicted just by knowing the action spectrum of a cell. We therefore analyzed the response profiles in greater detail, because they provide important information that is complementary to that from the threshold measurements described in a later section.

\section{Average color tuning}

In order to obtain a more complete description of the spectral tuning properties of different types of color-selective cells, we determined average tuning curves for $C B$ and $C O$ cells. Examples of individual tuning curves for each cell type are illustrated in Figure 14, $A$ and $C$. The corresponding average tuning curves are shown in Figure $14, B$ and $D$. These curves were constructed from normalized response curves recorded at maximal stimulus luminosity. The peaks were superimposed, and the discharge rates of the individual curves were averaged at 20 $\mathrm{nm}$ intervals from the peak. Cells with multiple peaks were excluded from the plots in order to accentuate basic differences in sharpness of tuning and response inhibition between $\mathrm{CB}$ and CO cells. The VP cell shown in Figure $14 A$ was broadly tuned to midspectral wavelengths, had poor responses to short and long wavelengths, and showed a strong white response typical for CB cells. The chromatic responses of $23 \mathrm{CB}$ units with a single peak were averaged in Figure $14 B$. The slope of the curve is steepest near the optimum and becomes increasingly shallow further away from the peak. Over the entire span, the mean response stays above the average background activity (stippling shows background $\pm 1 \mathrm{SD}$ ). The curve is reasonably symmetric about zero, and its full-width at half-maximum response above 


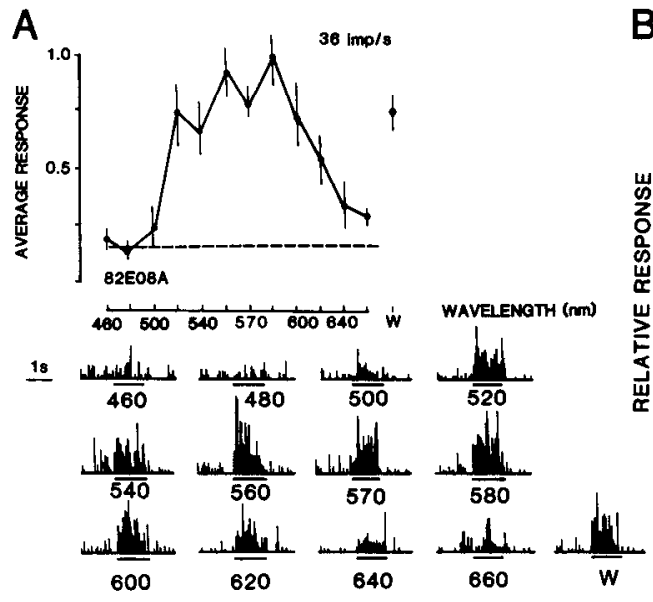

B
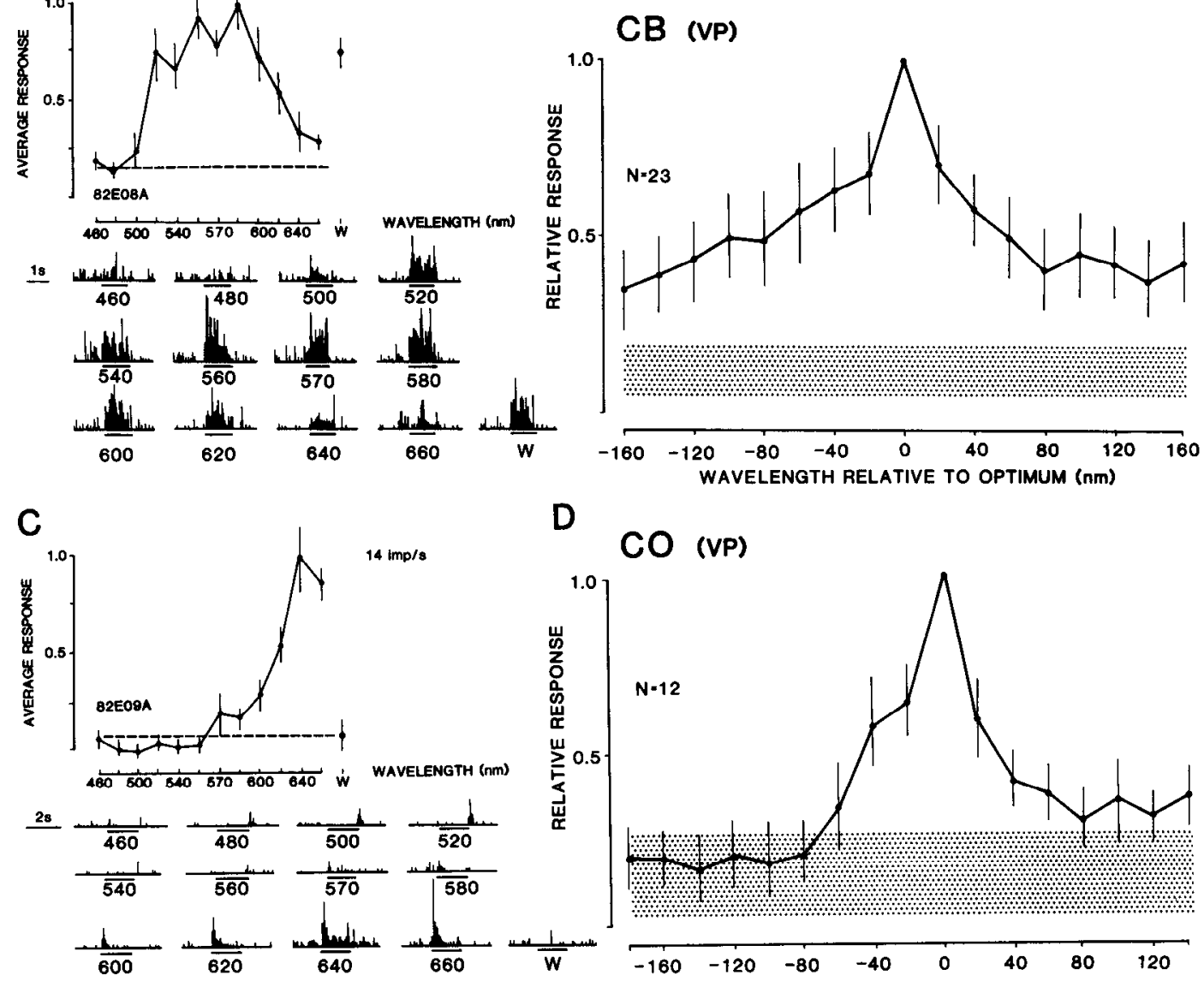

CO (VP)
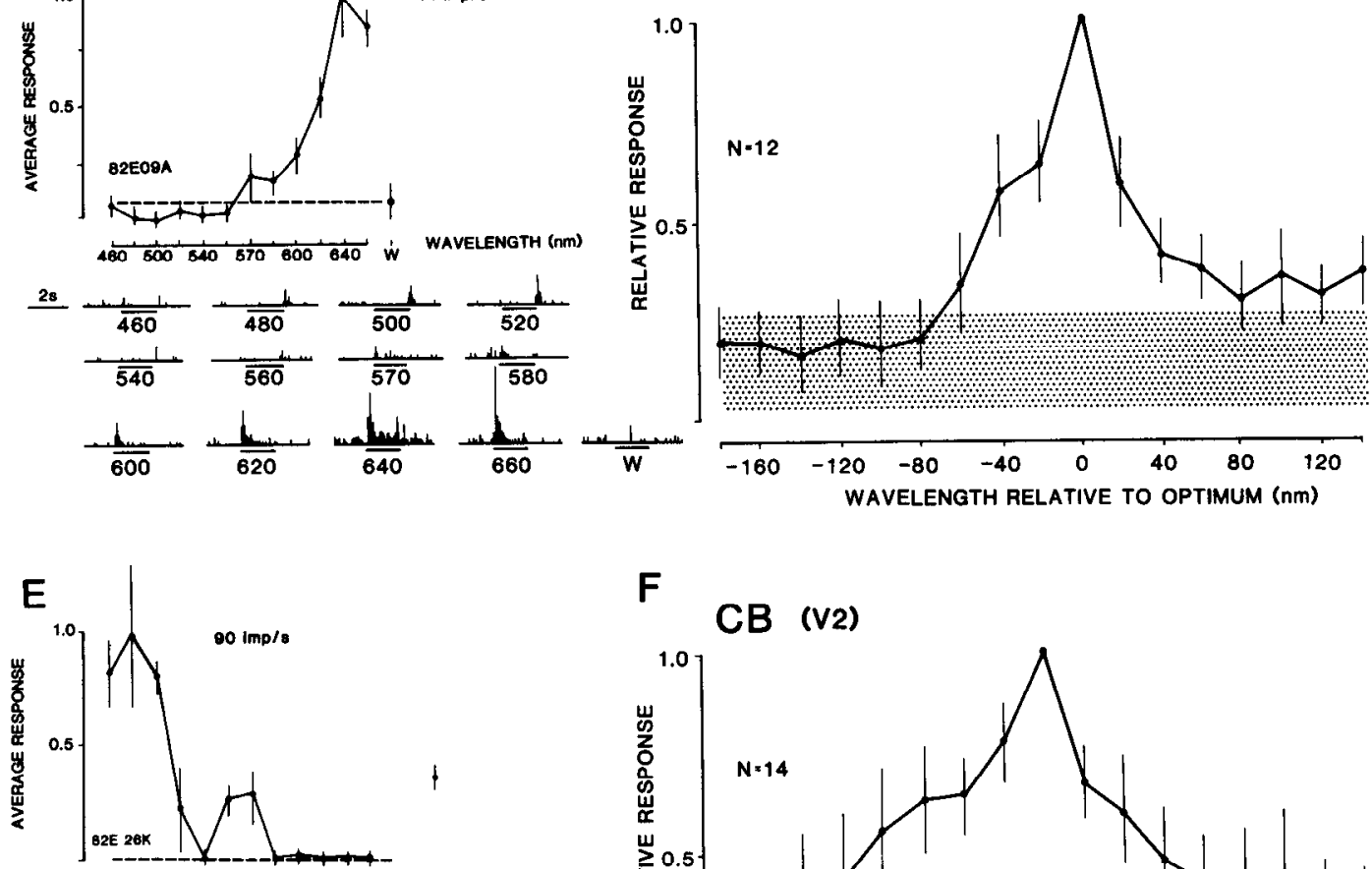

$\mathbf{F}$
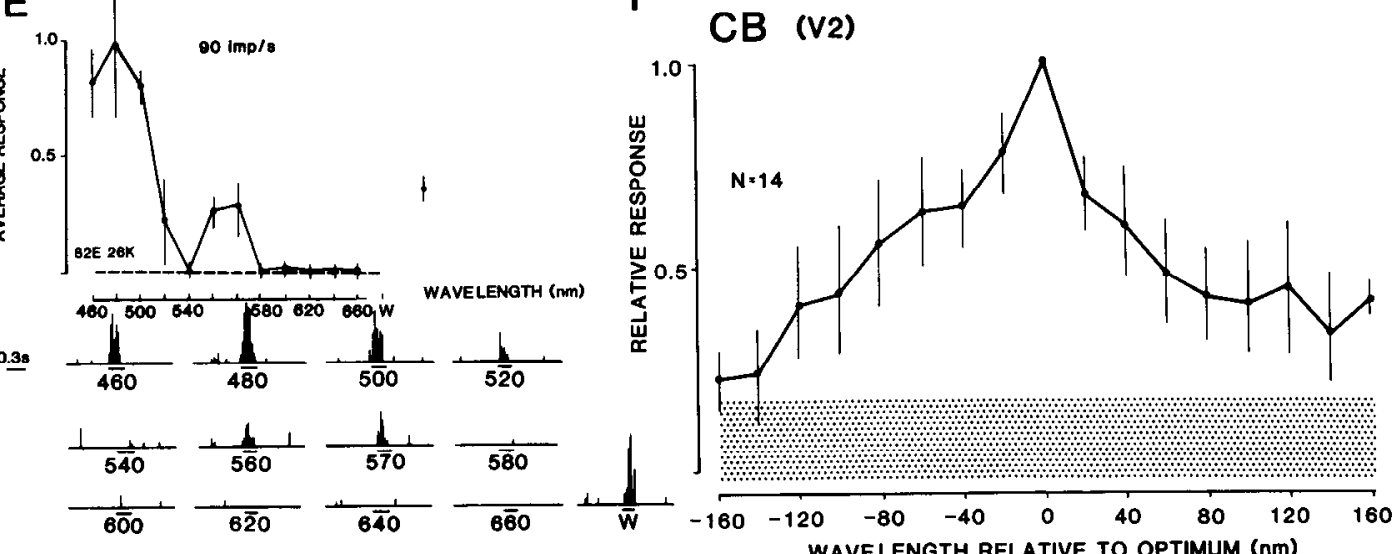

Figure 14. Spectral response curves and summed response histograms of color biased (CB) and color opponent (CO) cells in VP $(A-D)$ and ventral V2 $(E, F) . A$, Normalized response curve of a representative CB cell in VP with broad selectivity for midspectral and long wavelengths $(520-620$ $\mathrm{nm}$ ) and a strong response to white $(W)$. $B$, Average spectral tuning curve of $23 \mathrm{CB}$ cells in VP. Individual tuning curves were normalized to their greatest average rate of firing and each shifted so that their peak responses were superimposed. Bar, SD; stippling, the SD of the average normalized background rate of firing. $C$, Normalized response of a VP cell with CO properties. Short and midspectral wavelengths (460-560 $\mathrm{nm}$ ) elicited suppression followed by Off responses, long wavelengths $(580-660 \mathrm{~nm})$ elicited On responses, and white (W) was ineffective. $D$, Average normalized spectral tuning curve for $18 \mathrm{CO}$ and $\mathrm{CBO}$ units in VP. $E$, Normalized response curve of a $\mathrm{CB}$ unit in V2. $F$, Average normalized spectral tuning of $14 \mathrm{CB}$ cells in V2.

background is about $100 \mathrm{~nm}$, which is slightly narrower than the width of the tuning curve shown in Figure $14 A$.

Figure $14 C$ shows the response of a CO unit in VP to stationary flashed slits of different colors. As illustrated in the discharge histograms below, the cell gave an Off-response to short wavelengths and an On-response to long wavelengths. White light was not effective at all. The responses of $18 \mathrm{CO}$ and $\mathrm{CBO}$ units with a single peak were averaged and plotted in Figure 


$\begin{array}{ll}\text { CBO, } & \mathrm{CO} \\ \mathrm{CB} & \mathrm{N}=18 \\ \mathrm{~N}=33\end{array}$

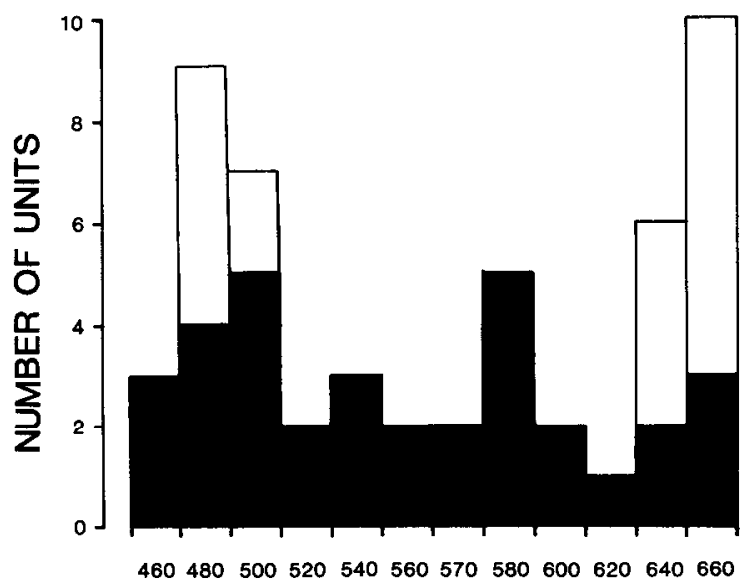

PREFERRED WAVELENGTH (nm)

Figure 15. Distribution of preferred wavelengths in VP of CB units (solid columns) and CBO, CO units (open columns). Entries for the 2 categories are plotted in nonoverlapping fashion, with the open columns starting where the solid ones leave off.

$14 D$. The curve drops sharply on both sides of the peak, diving into background activity on the left side and approaching it closely on the right. The shape of the tuning curve of $\mathrm{CO}$ units differs from $\mathrm{CB}$ units in 2 important respects: sharper tuning with a full-width at half-maximum of $60 \mathrm{~nm}$ and suppression of the response at wavelengths far from the optimum.

Figure $14 E$ depicts a response curve of a $\mathrm{CB}$ unit in $\mathrm{V} 2$, which represents the majority in our sample. It showed a relatively sharp spectral tuning and a good response to white. The average response curve is illustrated in Figure $14 F$ and represents the mean of 14 units with a single peak. The overall shape of the curve is similar to that described for CB cells in VP; the fullwidth at half-maximum, however, is $120 \mathrm{~nm}$, and thus slightly broader.

\section{Distribution of preferred wavelengths}

Figure 15 shows the distribution of preferred wavelengths at maximal stimulus brightness for $\mathrm{CB}$ (black columns) and $\mathrm{CO}$ and CBO units (white columns) in VP. Included in the histogram is the main peak of units with multiple peaks $(n=17)$. The preferred wavelengths of CB units are distributed fairly uniformly throughout the spectrum. The distribution of the preferred wavelength of $\mathrm{CO}$ and $\mathrm{CBO}$ units shows a distinct preference for either short or long wavelengths. There was no obvious difference in the preferred color between cells recorded at low and high eccentricities.

\section{Spectral sensitivity}

\section{Determination of action spectra}

Evaluations of color selectivity based on threshold responses provide information that is complementary to the suprathreshold measurements discussed in the preceding section. We made quantitative determinations of action spectra from families of response versus wavelength curves over a wide range of luminosities. The aim was to find the stimulus luminance that just produced a statistically significant change in the firing rate, relative to the spontaneous background activity. This was achieved by a stepwise lowering of the stimulus using neutral density filters interposed in the light path. In the course of such an attenuation series, the responses normally steadily decreased and eventually disappeared.

The process of obtaining relative thresholds is illustrated in Figure $16 A$ for a CB cell in VP. The threshold response to a given wavelength is defined as the point where the SEM response just starts to overlap with the SE of the average background activity. At full intensity ( 0.0 attenuation), for example, all but the $580 \mathrm{~nm}$ stimulus (asterisk) were judged to be suprathreshold. For progressively dimmer stimuli, threshold was reached over larger portions of the spectrum, until the stimuli were too dim ( $1.9 \mathrm{log}$ unit attenuation) to elicit significant responses for all wavelengths but $480 \mathrm{~nm}$. Sometimes at low stimulus luminosities the signal was quite noisy, and the response to a particular wavelength disappeared at one luminosity, reappeared above background for slightly dimmer stimuli, and finally disappeared again for still lower luminosity. In such cases, we took the mean of the values where the response disappeared as the cell's threshold for the wavelength under consideration.

This procedure furnished values of the relative threshold for each isoluminant color. To obtain spectral threshold curves, these numbers were converted into relative thresholds of intensity by correcting for the equal-luminosity compensation of the interference filters, or, in other words, the photopic spectral sensitivity of the eye (see Materials and Methods). The action spectrum derived for the cell illustrated in Figure $16 \mathrm{~A}$ is shown in Fig. 16B. Characteristically, the quantitatively determined threshold curves appear less smooth than those derived subjectively, in part because our stimulation paradigm necessitated separate test series for each stimulus luminosity, rather than interleaving of different luminosities within a single series. This cell was most sensitive to long wavelengths near the peak sensitivity of the red cones. Compared to the threshold curve of the red cone pigment (inset Fig. 16B), the cell was sensitive to a much narrower portion of the spectrum, which suggests an antagonistic input from green cones.

\section{Threshold curves}

Spectral sensitivity curves were determined from $\mathrm{CB}, \mathrm{CBO}$, and CO cells in V2 and VP, in order to obtain information on the input from the different types of cones and their mutual interactions. All action spectra were derived from threshold responses to spectral stimuli of optimal size, orientation, and direction of motion presented on a white background.

Eighteen color-selective VP units were tested (CB, 10; CBO, 3; $\mathrm{CO}, 5$ ); cxamples arc shown in Figurc 17. CB units 1-3 (Fig. $17 A$ ) were broadly tuned and had maximal spectral sensitivities at $560-570 \mathrm{~nm}$, between the peak sensitivities of green $(535$ $\mathrm{nm})$ and red cones $(570 \mathrm{~nm})$. The curves were slightly narrower than the spectral sensitivity curve of either cone type, suggesting a weak antagonistic input from either red cones (units 1,2 ) or green cones (unit 3). Similar indications of weak antagonistic cone interactions were found in other CB units tested.

As shown in Figure 17, $B$ and $C$, the threshold curves of CBO and $\mathrm{CO}$ units were different from $\mathrm{CB}$ units (Fig. 17A) in that the peak sensitivity was usually displaced from the maximal sensitivity of red and green cones toward longer wavelengths. The average half-bandwidth at half-maximal sensitivity $(0.3 \mathrm{log}$ unit), however, was only marginally narrower (CBO, CO: $19.5 \pm 4 \mathrm{~nm}$ vs CB: $20.7 \pm 5 \mathrm{~nm}$ ). CBO units 1 and 2 (Fig. $17 B$ ) presumably received their main input from red cones and a strong antagonistic input from green cones. In contrast, CBO unit 3 had a much less red-shifted peak sensitivity of $560 \mathrm{~nm}$. This, coupled with the finding of 2 peaks (at 460 and $570 \mathrm{~nm}$ ) in the suprathreshold response profile (Fig. 5D) suggests excitatory inputs from at least green and perhaps also blue cones. The shift in peak sensitivity away from midspectral wavelengths and the steep slopes of the curves were even more pronounced 


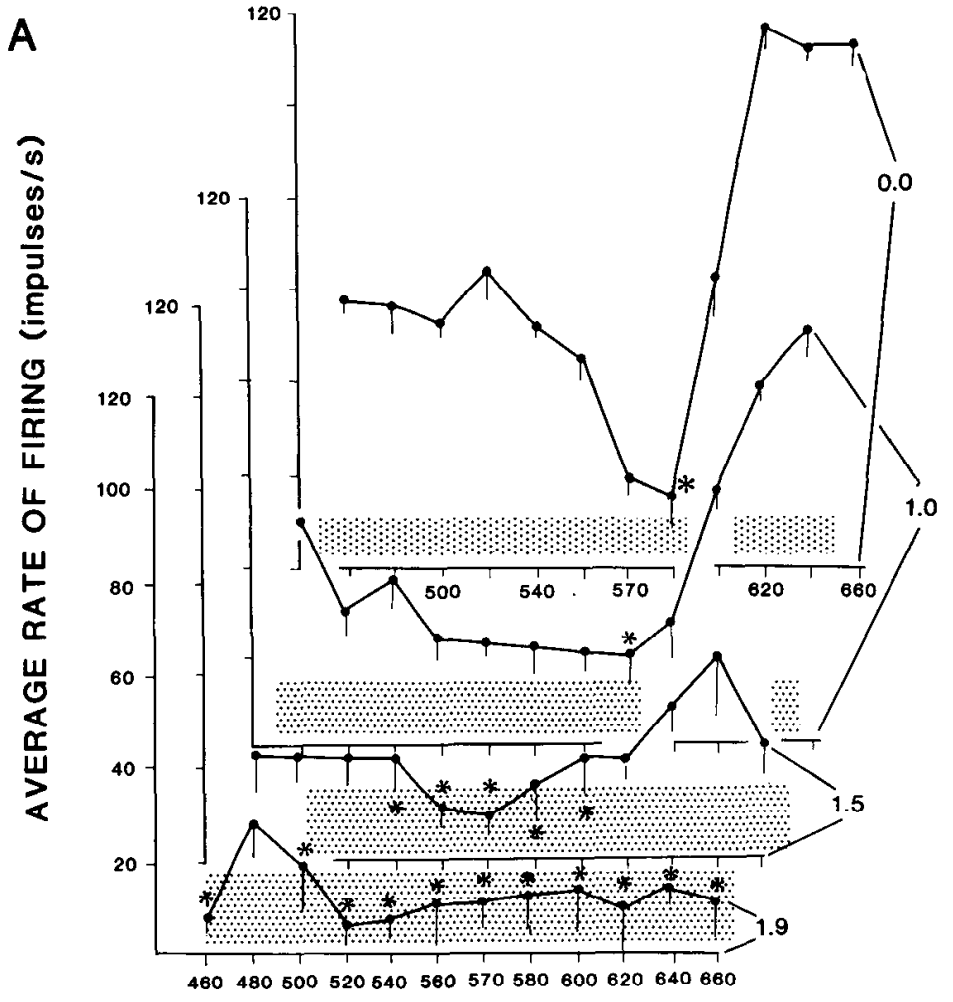

WAVE LENGTH (nm)

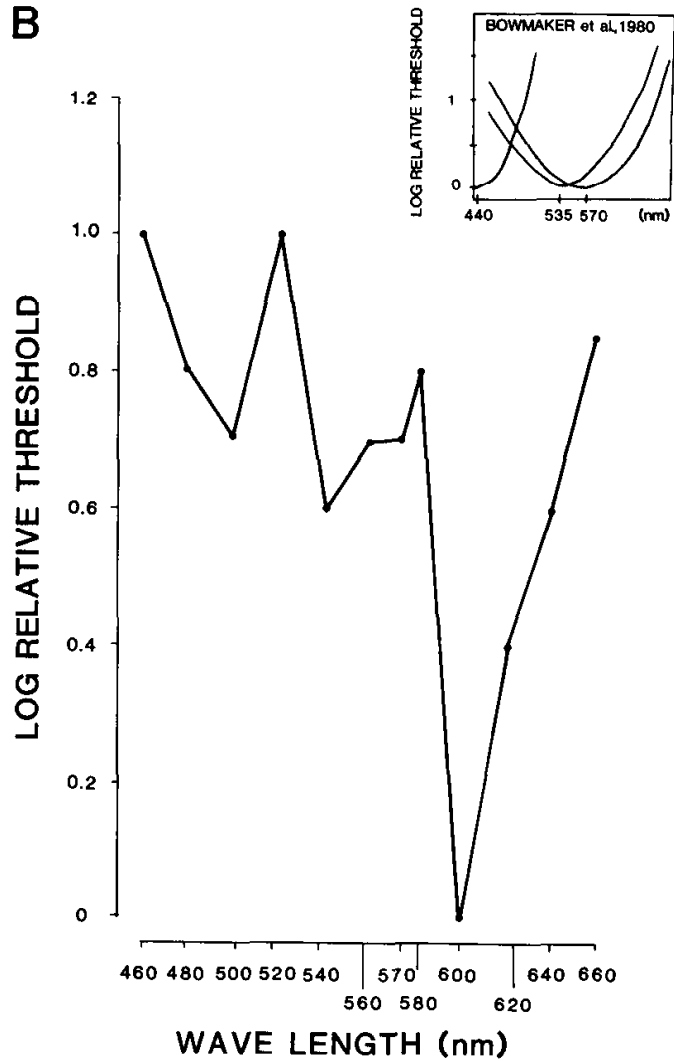

WAVE LENGTH (nm)

Figure 16. A, Determination of spectral threshold curves. Average spectral response curves ( 5 repetitions per wavelength) from a single VP unit were obtained at different stimulus luminosities (spanning $1.9 \mathrm{log}$ units attenuation). Bars, SD; stippling, \pm 1 SE of average normalized background rate of firing. Threshold responses are marked with asterisks to indicate that the response to a given wavelength is considered within the noise of the background activity. $B$, Action spectrum of the cell shown in $A$. It was obtained by correcting the threshold values for each wavelength for the relative photopic sensitivity at the corresponding spectral location (see text for details). Inset, Spectral threshold curves of blue, green, and red cones in macaque retina (adapted from Bowmaker et al., 1980).

in $\mathrm{CO}$ cells than in $\mathrm{CBO}$ cells (Fig. 17C). However, the mean half-width at half-maximal sensitivity of $\mathrm{CO}$ cells was indistinguishable from that of CBO cells.

We obtained threshold curves from a small sample of $6 \mathrm{CB}$ units in ventral V2. Three examples are illustrated in Figure $17 D$. Each of these units responded best to short wavelengths when tested with suprathreshold isoluminant stimuli. The suprathreshold response curves for units 1 and 3 are shown in Figures $14 E$ and $13 A$, respectively. The action spectra of all 3 units were asymmetric; the steeper slopes on the long wavelength side suggest that red cones antagonized an excitatory input from green cones, and probably also blue cones for unit 3 . The mean half-bandwidth at half-maximal sensitivity determined for the $6 \mathrm{CB}$ cells in V2 was $31.2 \pm 4 \mathrm{~nm}$, which was wider than for CB cells in VP $(20.7 \pm 5 \mathrm{~nm})$. However, this apparent difference may simply reflect the small sample size for $\mathrm{V} 2$.

Figure 18 shows the distribution of the peak spectral sensitivity for $\mathrm{CB}$ (black columns) and $\mathrm{CO}, \mathrm{CBO}$ cells (open columns) in VP. The histogram clearly shows that CB cells are maximally sensitive at midspectral locations (mean, $571 \pm 13 \mathrm{~nm}$ ), while the peaks of most $\mathrm{CO}$ cells were shifted toward longer wavelengths (mean, $595 \pm 23 \mathrm{~nm}$ ). The spectral sensitivity curves of the 2 opponent cells peaking at $560 \mathrm{~nm}$ were relatively flat at shorter wavelengths, suggesting a substantial blue cone input.

\section{Functional architecture}

\section{Polyfunctional neurons}

The results discussed thus far indicate that in VP and ventral V2 there is a high incidence of selectivity for color, orientation, and disparity and a low but significant incidence of direction selectivity. (All cells were also speed selective, but this parameter will not be considered further in the present section.) Because each cell was tested for many types of selectivity as time and recording stability permitted, it was possible to assess the degree to which multiple types of selectivities were present in individual cells. Tables 2 (VP) and 3 (V2) are formatted in a way that allows quick comparison between the overall incidence of each type of selectivity in the entire population (top row) and the incidence of that selectivity within subsets of the population that were also selective for another parameter. For example, the first column of Table 2 shows that the incidence of color selectivity in VP was $60 \%$ in the overall population, $69 \%$ among direction-selective cells, $48 \%$ among orientation-selective cells, and $61 \%$ among disparity-selective cells. Given the sample sizes, these percentages are not significantly different from one another. The same is true of the other types of selectivity in both VP and ventral V2. Thus, our results are consistent with the notion that the probability of any one cell having a particular type of selectivity is, to a first approximation, independent of whether that cell happens to have any other type of selectivity.

Of the 42 cells in VP tested for all 4 types of selectivities (direction, orientation, disparity, and color), 4 (9\%) were completely nonselective, $15(36 \%)$ were selective for 1 parameter, $16(38 \%)$ for $2,7(17 \%)$ for 3 , and none for all 4 parameters. This distribution is also consistent with all 4 types of selectivities occurring independently of one another, given the overall percentages shown in Tablc 2 . The sample of V2 cells tested to a comparable extent is very small but shows a similar trend (Table 3). 
A

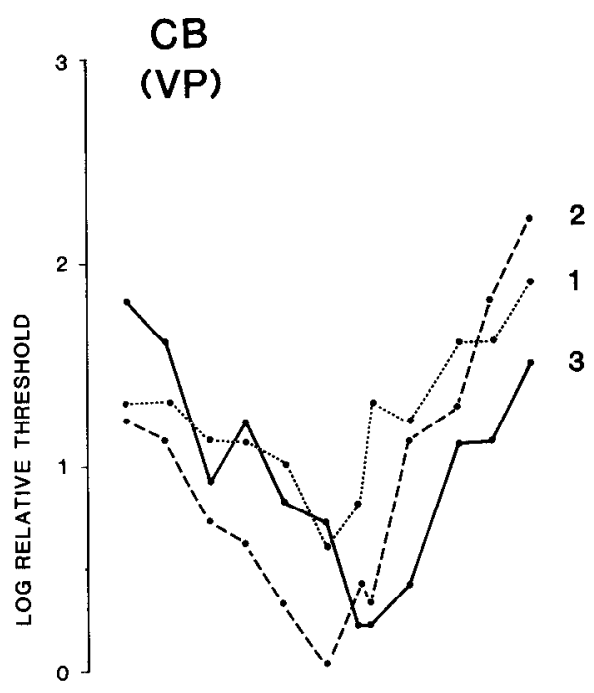

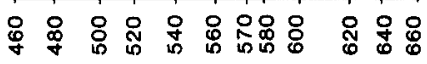

WAVELENGTH $(\mathrm{nm})$

C

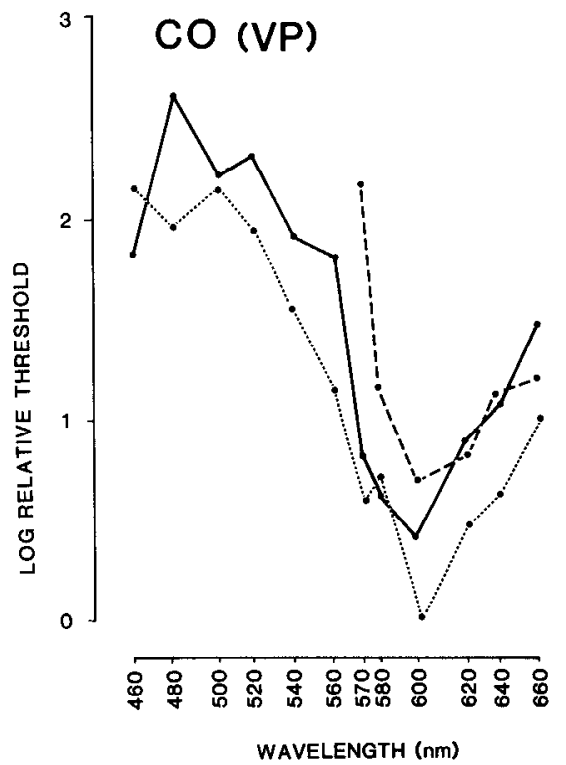

B

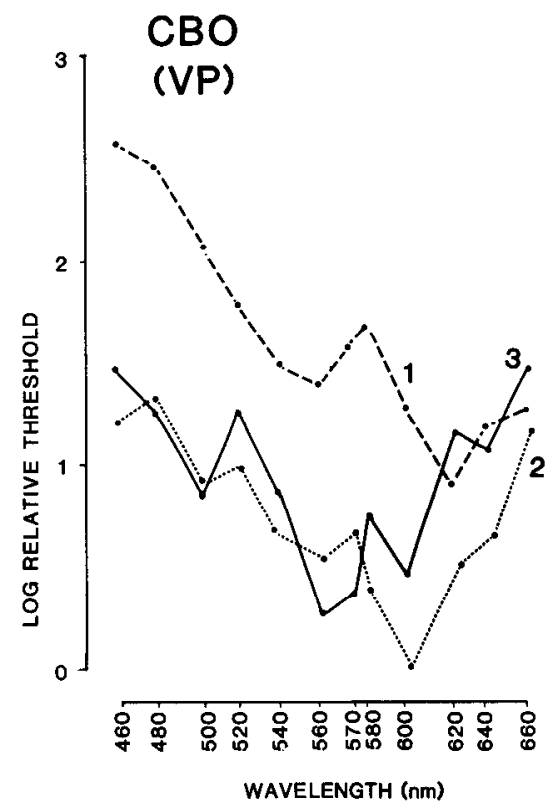

D

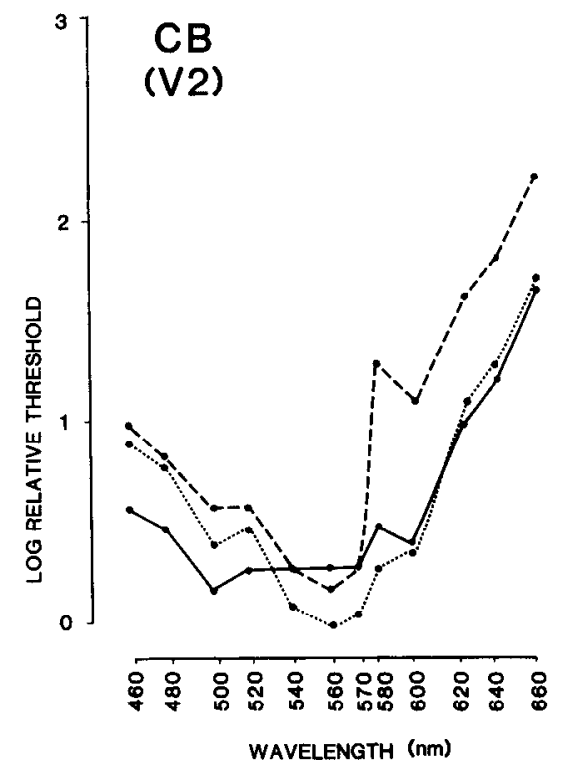

Figure 17. Representative examples of spectal threshold curves of color biased $\mathrm{CB}$ and $\mathrm{CBO}, \mathrm{CO}$ cells in VP $(A-C)$ and ventral V2 $(D)$. The curves are derived from average spectral tuning curves at different luminosity levels, as shown in Figure $16 A$. For each cell class, 3 examples (1-3) are illustrated and discussed in the text. in superficial layers and $16 \%(2 / 14)$ in lower layers. Even this difference may simply be a consequence of the small sample size.

\section{Functional clusters}

On many occasions, we had the impression that cells with similar functional properties tended to occur in clusters. This was assessed quantitatively by calculating in a single penetration the incidence of pairs of cells with similar properties. Two cells were considered a pair if their lateral separation, measured parallel to the pial surface, was within $0.25 \mathrm{~mm}$. The sample of units in V2 was too small to be analyzed. In the 47 pairs of VP cells analyzed (some cells being included in more than 1 pair), we were unable to confirm clustering in terms of the presence or absence of a particular type of selectivity (orientation, direction, disparity, or color). The probability that a cell selective for orientation, direction, disparity, or color was followed by a cell with the same type of selectivity was $0.42,0.12,0.45$, and 0.41 , 


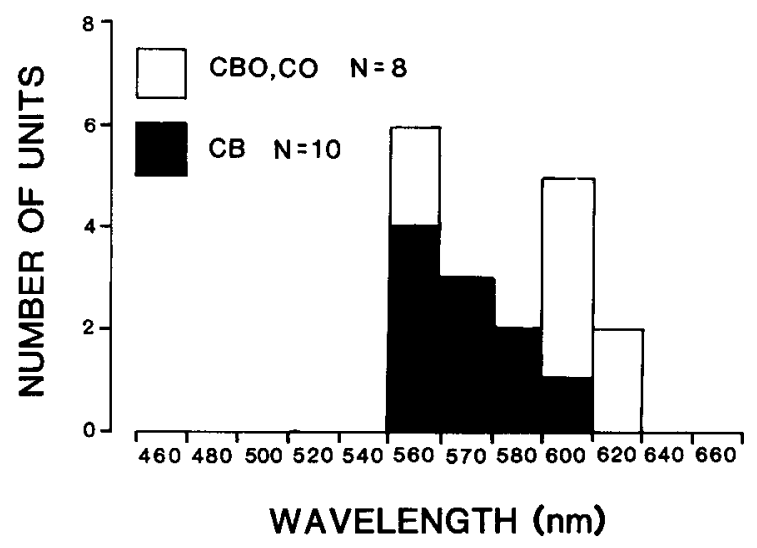

Figure 18. Distribution of peak spectral sensitivity of $10 \mathrm{CB}$ (solid columns) and $8 \mathrm{CO}$ cells (open columns) in VP.

respectively. None of these probabilities was significantly different from the chance incidence of the corresponding type of selectivity. However, a significant degree of clustering with a graininess of less than $0.1-0.2 \mathrm{~mm}$ could easily have gone undetected in our limited sample, in which relatively few pairs were separated by less than $0.1 \mathrm{~mm}$. In any event, there was a clear tendency for adjacent color-selective cells to have similar color preferences. This is shown in Figure 19, where the optimum wavelength for the first unit is plotted against the optimum wavelength for the succeeding (second) cell. Included in this plot are cells that did not respond to our monochromatic stimuli or to white light but that showed a vigorous response to black bars. There is an excellent correlation between the 2 peaks $(r=0.93)$, which suggests wavelength-specific clusters. Recordings from more than 2 successive color cells in a single traverse through cortex were rare. It is thus unclear what the spatial dimensions of these functional aggregates are in the radial and tangential dimensions.

\section{Discussion}

This study provides the first detailed analysis of the functional properties of neurons in area VP of the macaque monkey. It is also the first physiological study of ventral V2, providing a basis

\begin{tabular}{|c|c|c|c|c|}
\hline \multirow[b]{2}{*}{ Cell type } & \multicolumn{4}{|c|}{$\begin{array}{l}\text { Percentage (fraction) of cell type with conjoint selectiv- } \\
\text { ity }(\%)\end{array}$} \\
\hline & Color & Direction & Orientation & Disparity \\
\hline All & $60(49 / 81)$ & $13(13 / 96)$ & $57(42 / 73)$ & $53(36 / 58)$ \\
\hline Color & - & $20(9 / 46)$ & $44(14 / 32)$ & $52(17 / 33)$ \\
\hline Direction & $69(9 / 13)$ & - & $(2 / 3)$ & $(4 / 8)$ \\
\hline Orientation & $48(14 / 29)$ & $0(0 / 12)$ & - & $67(16 / 26)$ \\
\hline Disparity & $61(17 / 28)$ & $12(4 / 34)$ & $57(16 / 28)$ & - \\
\hline
\end{tabular}

Selectivity to each parameter was assessed quantitatively; in all cases, selectivity refers to cells having an index value $\geq 0.7$ (see text for details). Numbers in parentheses indicate the number of cells having the selectivity indicated by the heading at the top out of the subset of cells having the selectivity indicated at the far left. When the number of cells in the denominator is 10 or more, the percentage incidence is shown as an entry without parentheses. Because not all cells were tested for all parameters, the number of cells entered in the denominator for the various conjunctions is generally fewer than the number of selective cells in the numerator of the All category (first row). The incidence of orientation selectivity among direction-selective cells and vice versa involves only small numbers because only cells tested with stationary stimuli for orientation were included, thereby avoiding the confounding of orientation and direction selectivity as assayed with moving stimuli. For the remaining comparisons, the pool of orientation-selective cells was taken from both moving and stationary tests (cf. Fig. 7).

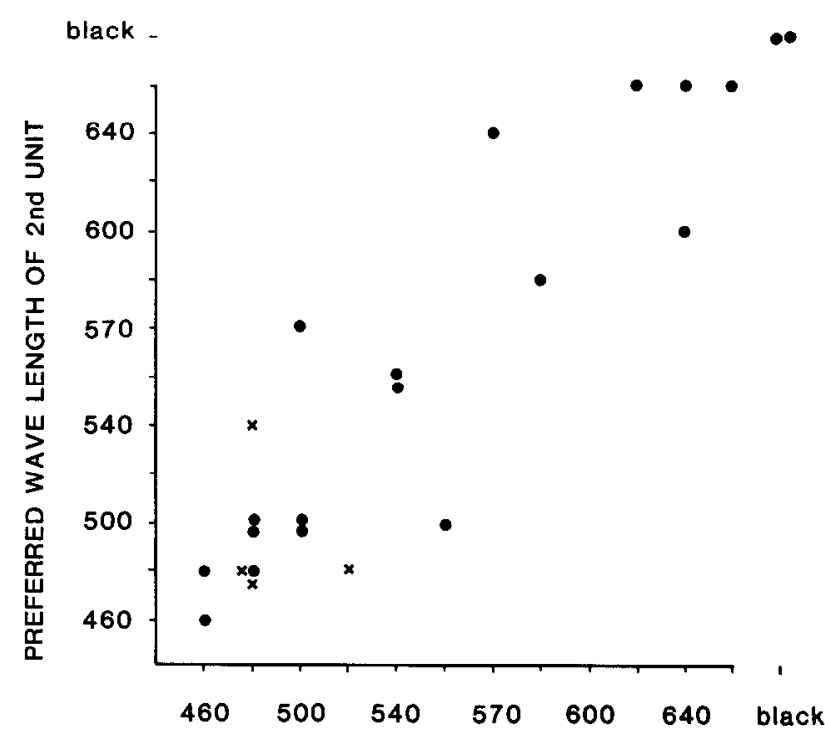

PREFERRED WAVE LENGTH OF 1st UNIT

$$
\begin{aligned}
& \text { - VP } \\
& \times V 2
\end{aligned}
$$

Figure 19. Peak spectral responses of successively recorded color-selective cells in VP (filled circles) and ventral V2 (crosses). The lateral distance, measured parallel to the pial surface, between the first and second units was less than $0.25 \mathrm{~mm}$.

for comparisons with several previous studies of dorsal V2. Our results relate to a number of general issues concerning visual processing and functional specialization, both at the level of single cells and at the level of cortical areas. As a prelude to a detailed discussion of these issues, it is useful to recapitulate the main findings.

1. In both VP and V2, the majority of cells were capable of signaling useful information about color, as judged by response curves to suprathreshold isoluminant stimuli.

2. In VP, we found no convincing evidence for distinct cell classes, based on the degree of color selectivity, the sharpness of tuning, or the distribution of preferred wavelengths. In V2, the sample was too small to draw firm conclusions either way.

3. Most cells appeared to have spatially homogeneous receptive fields with regard to chromatic properties as well as other properties tested. The average receptive field size in VP was considerably larger than in V2, which in turn was much larger than in V1.

4. Action spectra for color-selective cells had half-widths at half-height averaging $32 \mathrm{~nm}$ in V2 and $20 \mathrm{~nm}$ in VP. Qualitative

\begin{tabular}{|c|c|c|c|c|}
\hline \multirow[b]{2}{*}{ Cell type } & \multicolumn{4}{|c|}{$\begin{array}{l}\text { Percentage (fraction) of cell type with conjoint selectiv- } \\
\text { ity (\%) }\end{array}$} \\
\hline & Color & Direction & Orientation & $\overline{\text { Disparity }}$ \\
\hline All & $64(18 / 28)$ & $19(10 / 54)$ & $60(29 / 48)$ & $38(15 / 40)$ \\
\hline Color & - & $17(3 / 18)$ & $70(7 / 10)$ & $30(4 / 13)$ \\
\hline Direction & $(3 / 3)$ & - & $50(6 / 12)$ & $(3 / 5)$ \\
\hline Orientation & $64(7 / 11)$ & $(2 / 8)$ & - & $47(8 / 17)$ \\
\hline Disparity & $(4 / 5)$ & $23(3 / 13)$ & $80(8 / 10)$ & - \\
\hline
\end{tabular}
predictions of response patterns to suprathreshold stimuli could

Stimulus selectivity was assessed quantitatively (see text for details). Conventions as in Table 2. 
be made on the basis of action spectra for about half of the cells. In the remaining cases, however, the suprathreshold response profile was more complex and could not be inferred from threshold curves alone.

5. Most cells in VP and V2 were orientation selective; about half were disparity selective; a low percentage were direction selective, and nearly all were speed selective.

6. Many cells were selective for several stimulus parameters. The incidence of multiple selectivities was approximately that which would be expected if the probabilities of occurrence of different types of selectivity in any given cell were independent of one another.

How are these properties generated and how do they compare to single-unit properties in other cortical and subcortical visual centers? V2 receives its major ascending input from V1, and VP its major input from V2, placing them respectively at the second and third stages of a cortical hierarchy that has been hypothesized on the basis of connectional patterns (Maunsell and Van Essen, 1983c). Hence, it is sensible to begin with a comparison of receptive field properties between our results on V2 and VP and previous studies on lower visual centers, concentrating especially on color properties because of the complexity of processing in the chromatic domain.

\section{Retina and LGN}

Processing of color information begins at the photoreceptor stage with 3 cone types whose absorption maxima in vivo are approximately 440, 535, and $570 \mathrm{~nm}$ (Bowmaker et al., 1980). By the retinal ganglion cell (RGC) stage, several cell types have emerged that transmit chromatic information (DeMonasterio, 1978; DeMonasterio and Gouras, 1975). These relay through a corresponding set of LGN cells without obvious transformation of information content (Wiesel and Hubel, 1966). The cells most clearly implicated in color processing are concentrated in the parvicellular laminae. The most common parvicellular neurons (type I cells) have color-opponent, center-surround organization (e.g., red On-center, green Off-surround). They convey information containing a fundamental ambiguity about the spatial versus chromatic aspects of a stimulus. A small minority of parvicellular neurons (type II, ca. 7\%) have spatially uniform, color-opponent receptive fields and thus transmit a color signal unencumbered by information about spatial contrast. Quantitative studies by Derrington et al. (1984) suggest the overall population of LGN cells may have a continuous distribution in spatial organization, from completely concentric to completely uniform. In any event, the more relevant point in relation to the present study is that we generally used stimuli that were much larger than the receptive fields of individual RGC and LGN cells. Noncthcless, the population of cells activated by these large monochromatic stimuli would not be restricted to the stimulus borders (as would be the case for the achromatic cells of the magnocellular LGN layers). Rather, cells responsive to a given wavelength would be activated throughout the illuminated region, as has been graphically demonstrated by Nothdurft and Lee (1982).

Another important aspect of receptive field properties in the retina and LGN is that there is considerable variability in the balance between antagonistic center-surround mechanisms in different cells, ranging from near equality in some cells to strong dominance by the center mechanism in other cells (DeMonasterio and Schein, 1982; Derrington et al., 1984). To illustrate the significance of this variability, consider as examples 2 red On-center, green Off-surround cells, one having a perfectly balanced center-surround antagonism and the other having a center that strongly dominates the surround. The balanced cell will have a peak sensitivity in the red portion of the spectrum, will give an On response only over a narrow range of long wavelengths, and will not respond to uniform illumination with white light. In contrast, the unbalanced cell will have a peak sensitivity in the yellow-orange part of the spectrum (close to the absorption peak of the long-wavelength cones), will give an On-response over a relatively broad range, including yellow through red, and will respond well to white light. The action spectrum for the On (center) mechanism will be relatively broad for the unbalanced cell but quite narrow for the balanced cell. Given that there is a continuum in the degree of balance encountered in a population of cells (DeMonasterio and Schein, 1982), it follows that there is considerable heterogeneity in the functional inputs to V1.

\section{Receptive fields in $V 1$}

The encoding of color information in V1 has been addressed in studies from a number of different laboratories. Not surprisingly, the categorization of cells into qualitatively different response types has been done in a variety of ways, some emphasizing the spatial organization of receptive fields (e.g., Livingstone and Hubel, 1984), others emphasizing the types of action spectra determined from threshold measurements (e.g., Dow, 1974; Dow and Gouras, 1973; Michael, 1978a-c; Poggio et al., 1975), and still others emphasizing the response patterns to suprathreshold isoluminant stimuli (e.g., Bertulis et al., 1977; Vautin and Dow, 1985). These approaches are all complementary to one another, but the latter 2 are clearly the most relevant for comparison with the present study, inasmuch as we found little evidence for spatially heterogeneous receptive fields in either V2 or VP to which the V1 data could be related. Although there are various methodological and terminological differences that complicate the comparisons among these studies, several general conclusions can be drawn concerning the incidence and types of color selectivity in V1.

1. Information about stimulus color is conveyed by a large percentage of $\mathrm{V} 1$ cells, probably an outright majority of the whole population and of the cells in superficial layers in particular. Recent estimates of the incidence of cells variously described as selective, tuned, or biased for color ranges from 40 to $70 \%$, with the incidence somewhat greater for foveal versus extrafoveal V1 (Bertulis et al., 1977; Livingstone and Hubel, 1984; Poggio et al., 1975; Vautin and Dow, 1985; Zeki, 1983a). With the range of uncertainty of the assorted measurements, we conclude that there is no strong basis for suggesting a marked difference in the incidence of color selectivity in ventral V2 and $V P$ rclative to that in $V 1$.

2 . The sharpness of color tuning in V1, assayed in the aforementioned studies either by action spectra or by suprathreshold response curves, varies over a continuum, from broadband, nonselective responses to very sharply tuned cells with inhibition and/or Off-responses at wavelengths far from the optimum. The responsiveness to white stimuli also ranges across a continuum, with a tendency to be greater for cells that are more broadly tuned or whose preferred wavelength is midspectral. The occurrence of double-opponent properties in V1 (Livingstone and Hubel, 1984; Michael, 1978a, b) provides the ability to signal simultaneous spatial/color contrast, but whether it also leads to fundamentally sharper spectral tuning has not been reported.

3. When testing is done with isoluminant stimuli, the range of preferred wavelengths includes most of the visible spectrum, and there does not appear to be an especially biased representation of particular regions of the spectrum, at least outside of layer 4 (Bertulis et al., 1977; Vautin and Dow, 1985).

Thus, the major chromatic properties that we were able to analyze in V2 and VP are present to a comparable degree in V1 and are largely attributable to processing within the retina (except for double opponency, which has only been reported at the cortical level in primates). The primary difference in cortical versus subcortical chromatic properties has to do with the con- 
junction with other spatial attributes, particularly selectivity for stimulus orientation and binocular disparity. On the other hand, the occurrence of cells with multiple, well-defined peaks in widely separate parts of the spectrum has not to our knowledge been reported in V1, and their presence in VP ( $c f$. Figs. $5 D, 12 A$, $14 B$ ) may reflect an integrative process taking place in extrastriate cortex.

The relationship between color and orientation selectivity in $V l$ is of particular interest, because it is intimately linked to a functional dichotomy that in turn is related to the histochemical pattern of cytochrome oxidase activity in the superficial layers of V1. One functional stream includes the cytochrome oxidaserich "blobs," which receive direct LGN inputs and contain cells that lack orientation selectivity and are color selective, with either a double-opponent or a " $3 / 4$ double-opponent" concentric receptive field organization (Fitzpatrick et al., 1983; Livingstone and Hubel, 1982, 1984). A second functional stream includes the "interblobs," which receive inputs relayed from layers $4 \mathrm{~A}$ and $4 \mathrm{C} \beta$ and contain orientation-selective cells, a high percentage of which are also color selective, especially if one does not exclude cells from being considered color selective just because they respond well to white (see Van Essen, 1985). A third stream, largely achromatic in information content, arises from the magnocellular portion of the $L G N$ and involves layers $4 \mathrm{C} \alpha$ and $4 \mathrm{~B}$ of $\mathrm{V} 1$.

V2 receives major inputs from both blob and interblob regions of layers 2 and 3 in V1 (Livingstone and Hubel, 1984). It also receives a substantial input from layer $4 \mathrm{~B}$ of $\mathrm{V1}$ (Lund et al., 1981; Van Essen et al., 1986), which has been shown to be enriched in direction-selective cells relative to the overall V1 population (Dow, 1974; Livingstone and Hubel, 1984). The receptive field properties we encountered in ventral V2 are consistent with projections from all 3 streams: the high incidence of color-selective cells, many of which were orientation selective, might originate from both interblobs and blobs in V1, while the low, but significant, incidence of direction selectivity might be driven primarily via the layer $4 \mathrm{~B}$ projection dominated by the magnocellular stream. For VP, the high incidence of color selectivity and orientation selectivity, coupled with the low (13\%) incidence of direction selectivity, suggests that its inputs may derive primarily from the color and color-orientation streams, but this does not argue strongly against a moderate input from the achromatic-magnocellular stream.

Disparity selcetivity is present in a majority of V1 cells, including layer 4B as well as more superficial layers (Poggio, 1984; Poggio and Fischer, 1977; Poggio and Talbot, 1981). Thus, it is not surprising that we encountered disparity selectivity in roughly half of V2 and VP samples. Disparity tuning was in general not as sharp in the present study as in the aforementioned reports on V1 and V2. It is unclear whether this discrepancy is related to experimental conditions (alert vs anesthetized, paralyzed animals) or to the size or eccentricity of receptive fields (Ferster, 1981; Poggio and Talbot, 1981).

\section{Comparison with other extrastriate areas}

There are several obvious issues of interest in comparing the present results with previous studies on extrastriate visual areas, particularly V3, V4, MT, and dorsal V2. As with the comparison to $\mathrm{V} 1$, the issues are to some extent confounded by methodological differences, with some studies carried out using purely subjective criteria and others using quantitative indices.

\section{Dorsal vs ventral V2}

Our results on ventral V2 are similar to several previous studies with regard to the incidence of direction selectivity $(19 \%$ in ventral V2 vs 10-20\% in dorsal V2; Baizer et al., 1977; DeYoe and Van Essen, 1985; Van Essen and Zeki, 1978; Zeki, 1978) and of disparity selectivity (62\% in ventral V2 vs $43-50 \%$ in dorsal V2; Hubel and Wiesel, 1970; Poggio and Fischer, 1977). We also agree with Poggio and Fischer that among disparityselective cells, the tuned excitatory cells outnumber the near and far cells to a greater degree in V2 than in V1. There is greater diversity in the reported incidence of orientation selectivity in dorsal V2, 33\% (Baizer et al., 1977) vs 75\% (Van Essen and Zeki, 1978; Zeki, 1978). This discrepancy is probably a reflection of different criteria for classification as orientation selective. In any event, we obtained an intermediate estimate of $60 \%$ for ventral V2.

The largest discrepancy concerns the reported incidence of color selectivity, which has been reported to be quite low (4$16 \%$ ) in dorsal V2 (Baizer et al., 1977; Van Essen and Zeki, 1978; 'Zeki, 1978), in contrast to our estimate of $64 \%$ for a rather small sample in ventral V2. However, selectivities were assessed qualitatively, and cells that responded well to white were generally not classified as color selective in the aforementioned studies of dorsal V2; a similar criterion (WI $\geq 0.7$ ) applied to our ventral V2 data leads to an incidence of $11 \%$ cells that were classified as CO or CBO in Table 3. On the other hand, a recent quantitative analysis (DeYoe and Van Essen, 1985) of multiunit responses in dorsal $\mathrm{V} 2$ yielded a markedly higher incidence of color selectivity ( $40 \%$ CO and CB responses) when judged by the same criteria used in the present study. Presumably, the percentage would be even higher for single units than for multiunit recording. It is also possible that the discrepancies between the different studies are partly attributable to sampling bias in subregions of V2, which greatly differ in their incidence of colorselective cells (DeYoe and Van Essen, 1985; Hubel and Livingstone, 1985; Shipp and Zeki, 1985). Thus, it seems likely that when similar criteria are applied, there is no dramatic difference in the incidence of color selectivity or any other of the basic properties examined to date in dorsal and ventral V2.

\section{V3 vs VP}

The strip of cortex that we call VP was previously considered to be continuous with and an integral part of area V3 (Cragg, 1969; Zeki, 1969). There are several independent lines of evidence that VP and V3 differ to such a degree that it is appropriate to consider them as separate visual areas. This evidence and the associated arguments have been discussed at length elsewhere (Burkhalter et al., 1986; Van Essen, 1985; Van Essen ct al., 1986; Newsome et al., 1986). Here, we draw attention to the comparison of physiological properties in V3 and VP from the perspective of functional processing per se, rather than from the perspective of identifying and naming areas.

Two striking physiological differences have emerged from the comparison between VP in the present study and V3 as studied quantitatively using identical techniques and criteria by Felleman et al. (1984, and unpublished observations). First, the incidence of color selectivity is much greater in VP $(60 \%)$ than in V3 $(21 \%)$. Second, the incidence of direction selectivity is much lower in VP (13\%) than in V3 (40\%). The distributions of color and direction indices for the 2 areas are directly compared in Figure 7 of Burkhalter et al. (1986). The low incidence of color selectivity in V3 is also supported by previous qualitative studies (Baizer et al., 1977; Van Essen and Zeki, 1978; Zeki, 1978). The 2 areas are relatively similar in other respects, including orientation selectivity ( $57 \%$ in VP vs $76-85 \%$ in V3), disparity selectivity (53\% in VP vs $47 \%$ in V3), and speed selectivity (nearly all cells having preferred speeds in the range of $4^{\circ}-32^{\circ} \%$ $\mathrm{sec})$. Given that the visual representation is restricted to the upper part of the visual field in VP and to the lower part of the visual field in V3, the physiological differences between the 2 areas implies a major asymmetry in information processing in different parts of the visual field. It remains to be determined 
whether these differences are made up for by compensatory imbalances in other visual areas.

\section{$V P$ vs $V 4$ and $M T$}

The strongest evidence for functional specialization in extrastriate visual cortex comes from the contrast between areas MT and V4. MT, also known as V5 (Shipp and Zeki, 1985), is a well-defincd arca containing a very high percentage of dircetionselective cells (Albright et al., 1984; Dubner and Zeki, 1971; Maunsell and Van Essen, 1983a; Zeki, 1974a). In addition, MT contains cells selective for binocular disparity (Maunsell and Van Essen, 1983b) and for changing disparity (Zeki, 1974b), as well as cells representing a wide range of preferred speeds (Maunsell and Van Essen, 1983a). Moreover, chemical lesions of MT produce deficits specifically related to motion analysis (Newsome et al., 1985). In contrast, V4 contains few direction-selective cells (Van Essen and Zeki, 1978; Zeki, 1978) but a high percentage of color-selective cells. At one time there was considerable controversy about the incidence of color selectivity in V4, with early estimates ranging from $100 \%$ (Zeki, 1973) to $20 \%$ (Schein et al., 1982), but more recent studies from the same laboratories appear to be in reasonable agreement that the incidence is a strong, but not overwhelming, majority (Desimone et al., 1985; Zeki, 1983a). The incidence of orientation selectivity is also high in V4, 40-60\% (Schein et al., 1982; Zeki, 1983a), and on these grounds, as well as the fact that V4 provides a major input to inferotemporal cortex (Desimone et al., 1980; Felleman and Van Essen, 1983; Kuypers et al., 1965; Rockland and Pandya, 1979), it is reasonable to infer that V4 may be heavily involved in both form and color vision. In this regard, $\mathrm{V} 4$ and $\mathrm{VP}$ are very similar in their physiological response profiles for all parameters that have been extensively tested in both areas. There are additional properties that have been identified in some V4 cells, most notably an influence of receptive field surround mechanisms on the chromatic properties of the excitatory receptive field (Desimone and Schein, 1983; Zeki, $1983 \mathrm{~b}$ ). These surround effects, which may contribute to the perceptual stability of object colors under widely varying illumination conditions, were not found in V1 (Zeki, 1983b) and have not as yet been tested for in VP.

\section{Concluding remarks}

It is noteworthy that all of the major receptive field properties described in the present report represent stimulus selectivities that are already present in V1, having been generated therein or at subcortical levels. Moreover, at least under conditions of general anesthesia, the sharpness of tuning for various parameters is no better in V2 and VP than in V1, suggesting that once a basic type of selectivity is established, it does not improve markedly at higher stages of processing. However, this does not imply that V2 and VP do nothing major in the way of transforming the messages encoded at the single-cell level. Rather, it is more likely a reflection of our stimulation paradigm, which was intentionally limited to the testing of selectivity for a few basic stimulus parameters. With this information as a guide to the modalities of potentially greatest importance in each area (e.g., form and color in VP), future studies employing more complex stimuli should lead to a more comprehensive picture of visual processing in higher cortical areas.

\section{References}

Albright, T. D., R. Desimone, and C. G. Gross (1984) Columnar organization of directionally selective cells in visual area MT of the macaque. J. Neurophysiol. 51: 16-31.

Baizer, J. S. (1982) Receptive field properties of V3 neurons in monkey. Invest. Ophthalmol. 23: 87-95.

Baizer, J. S., D. L. Robinson, and B. M. Dow (1977) Visual responses of area 18 neurons in awake, behaving monkey. J. Neurophysiol. 40: 1024-1037.

Baker, J., S. E. Petersen, W. T. Newsome, and J. M. Allman (1981) Visual response properties of neurons in four extrastriate visual areas of the owl monkey (Aotus trivirgatus): A quantitative comparison of medial, dorsomedial, dorsolateral and middle temporal areas. J. Ncurophysiol. 45: 397-416.

Barlow, H. B., C. Blakemore, and J. P. Pettigrew (1967) The neural mechanism of binocular depth discrimination. J. Physiol. (Lond.) 193: 327-342.

Bertulis, A., C. Guld, and M. A. Lennox-Buchthal (1977) Spectral and orientation specificity of single cells in foveal striate cortex of the vervet monkey, Cercopithecus aethiops. J. Physiol. (Lond.) 268: 120.

Bowmaker, J. K., H. J. A. Dartnall, and J. D. Mollon (1980) Microspectrophotometric demonstration of four classes of photoreceptor in an old world primate, Macaca fascicularis. J. Physiol. (Lond.) 298 : 131-143.

Burkhalter, A., and D. C. Van Essen (1983) The connections of the ventral posterior arca (VP) in the macaque monkey. Soc. Neurosci. Abstr. 9: 153.

Burkhalter, A., D. J. Felleman, W. T. Newsome, and D. C. Van Essen (1986) Anatomical and physiological asymmetries related to visual areas V3 and VP in macaque extrastriate cortex. Vision Res. 26: 63 80.

Cragg, B. G. (1969) The topography of the afferent projections in the circumstriate visual cortex of the monkey studied by the Nauta method. Vision Res. 5: 733-747.

Cyander, M., and D. Regan (1978) Neurons in cat parastriate cortex sensitive to the direction of motion in three-dimensional space. J. Physiol. (Lond.) 274: 549-569.

DeMonasterio, F. M. (1978) Properties of concentrically organized X and Y ganglion cells of macaque retina. J. Neurophysiol. 41: 13941417 .

DeMonasterio, F. M., and P. Gouras (1975) Functional properties of ganglion cells of the rhesus monkey retina. J. Physiol. (Lond.) 251: 167-195.

DeMonasterio, F. M., and S. J. Schein (1982) Spectral bandwidths of color-opponent cells of geniculocortical pathway of macaque monkeys. J. Neurophysiol. 47: 214-224.

Derrington, A. M., J. Krauskopf, and P. Lennie (1984) Chromatic mechanisms in lateral geniculate nucleus of macaque. J. Physiol. (Lond.) 357: 241-265.

Desimone, R., and S. J. Schein (1983) Receptive field properties of neurons in visual area V4 of the macaque. Soc. Neurosci. Abstr. 9: 153.

Desimone, R., J. Fleming, and C. G. Gross (1980) Prestriate afferents to inferior temporal cortex: An HRP study. Brain Res. 184: 41-55.

Desimone, R., S. J. Schein, J. Morgan, and L. Ungerleider (1985) Contour, color and shape analysis beyond the striate cortex. Vision Res. 25: 441-452.

DeYoe, E. A., and D. C. Van Essen (1985) Segregation of efferent connections and receptive field properties in visual area V2 of the macaque. Nature $317: 58-61$.

Dow, B. M. (1974) Functional classes of cells and their laminar distribution in monkey visual cortex. J. Neurophysiol. 37: 927-946.

Dow, B. M., and P. Gouras (1973) Color and spatial specificity of single units in rhesus monkey foveal striate cortex. J. Neurophysiol. 36: $79-100$

Dubner, R., and S. M. Zeki (1971) Response properties and receptive fields of cells in an anatomically defined region of the superior temporal sulcus. Brain Res. 35: 528-532.

Felleman, D. J., and D. C. Van Essen (1983) The connections of area V4 of macaque monkey extrastriate cortex. Soc. Neurosci. Abstr. 9: 153.

Felleman, D. J., G. J. Carman, and D. C. Van Essen (1984) Evidence for distinction between areas V3 and VP of macaque extrastriate cortex. Invest. Ophthalmol. Vis. Sci. 25: 278.

Ferster, D. (1981) A comparison of binocular depth mechanisms in areas 17 and 18 of cat visual cortex. J. Physiol. (Lond.) 311: 623655.

Fitzpatrick, D., K. Itoh, and I. T. Diamond (1983) The laminar organization of the lateral geniculate body and the striate cortex in the squirrel monkey (Saimiri sciureus). J. Neurosci. 3: 673-702. 
Gattass, R., C. G. Gross, and J. H. Sandell (1981) Visual topography of V2 in the macaque. J. Comp. Neurol. 201: 519-539.

Hubel, D. H., and M. S. Livingstone (1985) Complex unoriented cells in a subregion of primate area 18 . Nature $315: 325-327$.

Hubel, D. H., and T. N. Wiesel (1968) Receptive fields and functional architecture of monkey striate cortex. J. Physiol. (Lond.) 195: 215243.

Hubel, D. H., and T. N. Wiesel (1970) Cells sensitive to binocular depth in area 18 of the macaque monkey cortex. Nature 225:41-43.

Kuypers, H. G., M. K. Szwarcbart, M. Mishkin, and H. E. Rosvold (1965) Occipitotemporal cortico-cortical connections in the rhesus monkey. Exp. Neurol. 11: 245-262.

Livingstone, M. S., and D. H. Hubel (1982) Thalamic inputs to cytochrome oxidase-rich regions in monkey visual cortex. Proc. Natl Acad. Sci. USA 79: 6098-6101.

Livingstone, M. S., and D. H. Hubel (1984) Anatomy and physiology of a color system in the primate visual cortex. J. Neurosci. 4: 309356.

Lund, J. S., A. E. Hendrickson, M. P. Ogren, and E. A. Tubin (1981) Anatomical organization of primate visual cortex area VII. J. Comp. Neurol. 202: 19-45.

Maunsell, J. H. R., and D. C. Van Essen (1983a) Functional properties of neurons in middle temporal visual area of the macaque monkey. I. Selectivity for stimulus direction, speed and orientation. J. Neurophysiol. 49: 1127-1147.

Maunsell, J. H. R., and D. C. Van Essen (1983b) Functional properties of neurons in middle temporal visual area of the macaque monkey. II. Binocular interactions and sensitivity to binocular disparity. J. Neurophysiol. 49: 1148-1167.

Maunsell, J. H. R., and D. C. Van Essen (1983c) The connections of the middle temporal visual area (MT) and their relationships to a cortical hierarchy in the macaque monkey. J. Neurosci. 3: 2563-2586.

Michael, C. D. (1978a) Color vision mechanisms in monkey striate cortex: Dual-opponent cells with concentric receptive fields. J. Neurophysiol. 41: 572-588.

Michael, C. D. (1978b) Color vision mechanisms in monkey striate cortex: Simple cells with dual opponent-color receptive fields. J. Neurophysiol. 41: 1233-1249.

Michael, C. D. (1978c) Color-sensitive complex cells in monkey striate cortex. J. Neurophysiol. 41: 1250-1266.

Newsome, W. T., J. H. R. Maunsell, and D. C. Van Essen (1980) Areal boundaries and topographic organization of the ventral posterior area (VP) of the macaque monkey. Soc. Neurosci. Abstr. 6: 579.

Newsome, W. T., J. H. R. Maunsell, and D. C. Van Essen (1986) The ventral posterior visual area of the macaque: Visual topography and areal boundaries. J. Comp. Neurol. (in press).

Newsome, W. T., R. M. Wurtz, M. R. Dürsteler, and A. Mikami (1985) Deficit in visual motion processing following ibotenic acid lesions of the middle temporal visual area of the macaque monkey. J. Neurosci. 5: 825-840.

Nothdurft, H. C., and B. B. Lee (1982) Responses to coloured patterns in the macaque lateral geniculate nucleus: Pattern processing in single neurones. Exp. Brain Res. 48: 43-54.

Orban, G. A., H. Kennedy, and H. Maes (1981) Response to movement of neurons in areas 17 and 18 of the cat: Velocity sensitivity. J. Neurophysiol. 45: 1043-1058.

Poggio, G. F. (1984) Processing of stereoscopic information in primate visual cortex. In Dynamic Aspects of Neocortical Function, G. M. Edelman, W. E. Gall, and W. M. Cowan, eds., pp. 613-636, Wiley, New York.

Poggio, G. F., and B. Fischer (1977) Binocular interactions and depth sensitivity in striate and prestriate cortex of behaving rhesus monkey. J. Neurophysiol. 40: 1392-1405.

Poggio, G. F., and W. H. Talbot (1981) Mechanisms of static and dynamic stereopsis in foveal cortex of the rhesus monkey. J. Physiol. (Lond.) 315: 469-492.
Poggio, G. F., F. H. Baker, R. J. W. Mansfield, A. Sillito, and P. Grigg (1975) Spatial and chromatic propertics of ncurons subserving foveal and parafoveal vision in rhesus monkey. Brain Res. 100:25-59.

Rockland, K. S., and Pandya, D. N. (1979) Laminar origins and terminations of cortical connection of the occipital lobe in the rhesus monkey. Brain Res. 179: 3-20.

Schein, S. J., R. T. Marrocco, and F. M. DeMonasterio (1982) Is there a high concentration of color-selective cells in area V4 of monkey visual cortex? J. Neurophysiol. 47: 193-213.

Schiller, P. H., B. L. Finlay, and S. F. Volman (1976) Quantitative studies of single cell properties in monkey striate cortex. I. Spatiotemporal organization of receptive fields. J. Neurophysiol. 39: 12881319.

Shipp, S., and S. Zeki (1985) Segregation of pathways leading from area V2 to areas V4 and V5 of macaque monkey visual cortex. Nature 315: 322-325.

Ungerleider, L. G., and M. Mishkin (1982) Two cortical visual systems. In Analysis of Visual Behavior, D. Ingle, M. Goodale, and R. Mansfield, eds., pp. 549-586, MIT Press, Cambridge, MA.

Van Essen, D. C. (1985) Functional organization of primate visual cortex. In Cerebral Cortex, Vol. 3, E. G. Jones and A. Peters, eds., pp. 259-329, Plenum, New York.

Van Essen, D. C., and J. H. R. Maunsell (1980) Two-dimensional maps of the cerebral cortex. J. Comp. Neurol. 191: 25-281.

Van Essen, D. C., and J. H. R. Maunsell (1983) Hierarchical organization and functional streams in the visual cortex. Trends Neurosci. 6: $370-375$.

Van Essen, D. C., and S. M. Zeki (1978) The topographic organization of rhesus monkey prestriate cortex. J. Physiol. (Lond.) 277: 193-226

Van Essen, D. C., J. H. R. Maunsell, and J. L. Bixby (1979) Areal boundaries and topographic organization of visual areas $\mathrm{V} 2$ and $\mathrm{V} 3$ in the macaque monkey. Soc. Neurosci. Abstr. 5: 812.

Van Essen, D. C., W. T. Newsome, and J. L. Bixby (1982) The pattern of interhemispheric connections and its relationship to extrastriate visual areas in the macaque monkey. J. Neurosci. 2: 265-283.

Van Essen, D. C., W. T. Newsome, J. H. R. Maunsell, and J. L. Bixby (1986) The projections from striate cortex (V1) to visual areas V2 and V3 in the macaque monkey: Asymmetries, areal boundaries, and patchy connections. J. Comp. Neurol. 244: 451-480.

Vautin, R. G., and B. M. Dow (1985) Color cell groups in foveal striate cortex of the behaving macaque. J. Neurophysiol. 54: 273-292.

Wiesel, T. N., and D. H. Hubel (1966) Spatial and chromatic interactions in the lateral geniculate body of the rhesus monkey. J. Neurophysiol. 29: 1115-1156.

Wiitanen, J. T. (1969) Selective silver impregnation of degenerating axons and axon terminals in the central nervous system of the macaque monkey (Macaca mulatta). Brain Res. 14: 540-548.

Zeki, S. M. (1969) Representation of central visual fields in prestriate cortex of monkey. Brain Res. 14: 271-291.

Zeki, S. M. (1973) Colour coding in rhesus monkey prestriate cortex. Brain Res. 53: 422-427.

Zeki, S. M. (1974a) Functional organization of a visual area in the posterior bank of the superior temporal sulcus of the rhesus monkey. J. Physiol. (Lond.) 236: 549-573.

Zeki, S. M. (1974b) Cells responding to changing image size and disparity in the cortex of the rhesus monkey. J. Physiol. (Lond.) 242 827-841.

Zcki, S. M. (1978) Uniformity and diversity of structure and function in rhesus monkey prestriate visual cortex. J. Physiol. (Lond.) 277: 273-290.

Zeki, S. M. (1983a) The distribution of wavelength and orientation selective cells in different areas of monkey visual cortex. Proc. R. Soc Lond. [Biol.] 217: 449-470.

Zeki, S. M. (1983b) Colour coding in the cerebral cortex: The reaction of cells in monkey visual cortex to wavelengths and colours. Neuroscience 9: 741-765. 